\title{
Unequal misses during the flash-induced advancement of photosystem II: effects of the $S$ state and acceptor side cycles
}

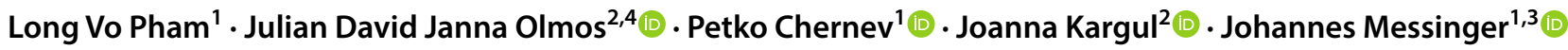

Received: 25 April 2018 / Accepted: 3 August 2018 / Published online: 6 September 2018

(c) The Author(s) 2018

\begin{abstract}
Photosynthetic water oxidation is catalyzed by the oxygen-evolving complex (OEC) in photosystem II (PSII). This process is energetically driven by light-induced charge separation in the reaction center of PSII, which leads to a stepwise accumulation of oxidizing equivalents in the OEC $\left(\mathrm{S}_{i}\right.$ states, $\left.i=0-4\right)$ resulting in $\mathrm{O}_{2}$ evolution after each fourth flash, and to the reduction of plastoquinone to plastoquinol on the acceptor side of PSII. However, the $\mathrm{S}_{i}$-state advancement is not perfect, which according to the Kok model is described by miss-hits (misses). These may be caused by redox equilibria or kinetic limitations on the donor (OEC) or the acceptor side. In this study, we investigate the effects of individual S state transitions and of the quinone acceptor side on the miss parameter by analyzing the flash-induced oxygen evolution patterns and the $S_{2}, S_{3}$ and $S_{0}$ state lifetimes in thylakoid samples of the extremophilic red alga Cyanidioschyzon merolae. The data are analyzed employing a global fit analysis and the results are compared to the data obtained previously for spinach thylakoids. These two organisms were selected, because the redox potential of $Q_{\mathrm{A}} / Q_{\mathrm{A}}^{-}$in PSII is significantly less negative in C. merolae $\left(E_{\mathrm{m}}=-104 \mathrm{mV}\right)$ than in spinach $\left(E_{\mathrm{m}}=-163 \mathrm{mV}\right)$. This significant difference in redox potential was expected to allow the disentanglement of acceptor and donor side effects on the miss parameter. Our data indicate that, at slightly acidic and neutral $\mathrm{pH}$ values, the $E_{\mathrm{m}}$ of $Q_{\mathrm{A}}{ }^{-} / Q_{\mathrm{A}}$ plays only a minor role for the miss parameter. By contrast, the increased energy gap for the backward electron transfer from $Q_{\mathrm{A}}{ }^{-}$to Pheo slows down the charge recombination reaction with the $\mathrm{S}_{3}$ and $\mathrm{S}_{2}$ states considerably. In addition, our data support the concept that the $S_{2} \rightarrow S_{3}$ transition is the least efficient step during the oxidation of water to molecular oxygen in the Kok cycle of PSII.
\end{abstract}

Keywords Photosynthesis · Photosystem II · Mechanism of water oxidation $\cdot$ Flash-induced oxygen oscillation pattern (FIOP) $\cdot$ Unequal miss parameter $\cdot$ Cyanidioschyzon merolae

This paper is dedicated to Govindjee who was honored, along with Bill Cramer and A.S. Rahavensdra, at the 8th International Conference on Photosynthesis and Hydrogen Energy Research for Sustainability, held in Hyderabad, in November, 2017.

Joanna Kargul

j.kargul@uw.edu.pl

$\bowtie$ Johannes Messinger

johannes.messinger@kemi.uu.se

1 Department of Chemistry - Ångström, Uppsala University, Lägerhyddsvägen 1, 75120 Uppsala, Sweden

2 Solar Fuels Lab, Centre of New Technologies, University of Warsaw, Banacha 2C, 02-097 Warsaw, Poland

3 Department of Chemistry, Chemistry Biology Center (KBC), Umeå University, Linnaeus väg 6, 90187 Umeå, Sweden

4 Present Address: Department of Molecular Biophysics, Faculty of Biochemistry, Biophysics, and Biotechnology, Jagiellonian University, Gronostajowa 7, 30-387 Kraków, Poland

\section{Introduction}

Cyanobacteria, algae, and higher plants capture sunlight to store its energy in the chemical bonds of carbohydrates, proteins, and lipids. The electrons and protons used for atmospheric $\mathrm{CO}_{2}$ fixation are extracted from water. The electrons are then energized to the reduction potential required for $\mathrm{CO}_{2}$ reduction in two light-driven charge separation reactions performed in the reaction centers of photosystems II (PSII) and photosystem I (PSI), and stabilized by multiple electron transfer events to allow the slow chemistry of water oxidation and $\mathrm{CO}_{2}$ fixation to occur. The side product of solar-driven water oxidation is molecular oxygen, which sustains all aerobic life on Earth (Govindjee et al. 2005; Renger 2008; Barber 2009; Shevela et al. 2012; Blankenship 2014; Cardona et al. 2015). 
The reaction sequence in the PSII complex, which catalyzes water oxidation to dioxygen, can be divided into three main events that occur at different time scales. Photon capture in the light-harvesting antenna of PSII and excitation energy transfer to the reaction center lead to the formation of the excited state of the primary donor, $\mathrm{P} 680^{*}$, which is a chlorophyll $(\mathrm{Chl})$ dimer. P680* transfers its excited electron within picoseconds to the primary acceptor pheophytin, Pheo (Fig. 1a) (Mamedov et al. 2015; Mirkovic et al. 2017; Romero et al. 2017). The subsequent electron transfer steps, which increase the spatial separation and decrease the potential difference between the photo-generated charge pair, minimize the chance for charge recombination reactions. These processes occur over a wide time span (10 ns-100 $\mu$ s) and include on the acceptor side electron transfer from $\mathrm{Pheo}^{\bullet-}$ to the firmly bound plastoquinone $Q_{\mathrm{A}}$, and further to the second, exchangeable plastoquinone, $Q_{\mathrm{B}}$. On the donor side, $\mathrm{P}_{680^{\circ}}{ }^{\circ}$ is reduced by tyrosine $Z, Y_{\mathrm{Z}}$ (D1-Tyr 161), which in turn oxidizes the oxygen-evolving complex (OEC) of PSII. Repetition of these steps allows for multi-electron and multiproton chemistry to occur at the $100 \mu \mathrm{s}-1 \mathrm{~ms}$ time scales. These reactions form plastohydroquinone on the acceptor side and molecular oxygen in the OEC on the donor side of PSII (Renger and Renger 2008; Blankenship 2014).

At the heart of the OEC is the $\mathrm{Mn}_{4} \mathrm{CaO}_{5}$ cluster (Fig. 1b, center). This inorganic core unfolds its full catalytic potential within the special protein and water environment of

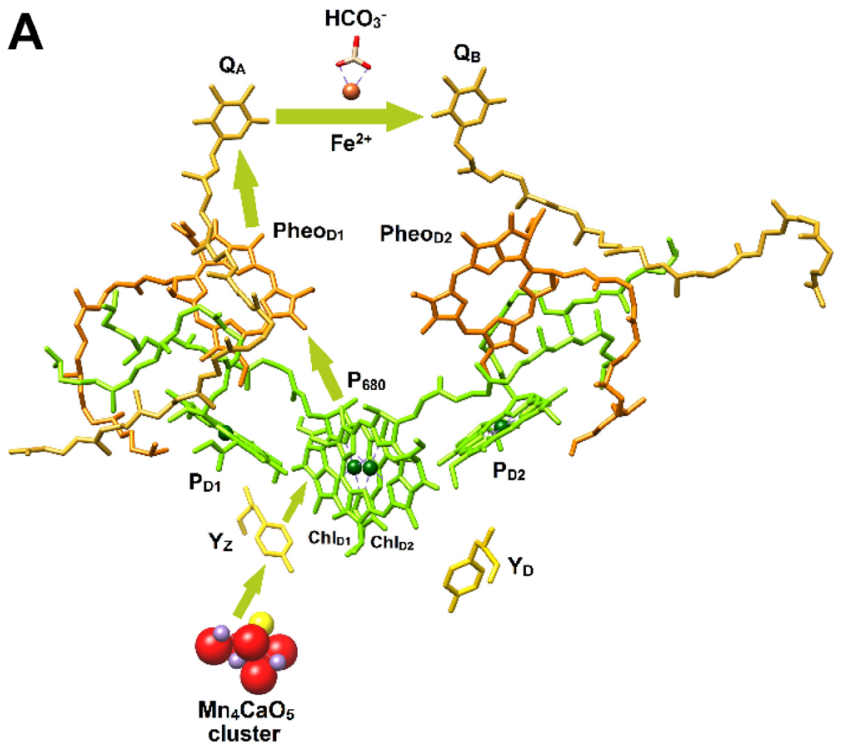

Fig. 1 The electron transfer cofactors of the PSII reaction center (left, a) and the Kok cycle of solar-driven water oxidation and the structure of the $\mathrm{Mn}_{4} \mathrm{CaO}_{5}$ cluster (right, b). $\mathrm{S}_{i}$-state-dependent miss parameters, proton release, and substrate water binding are indicated. Numbers on the arrows correspond to flash numbers driving the first cycle, which starts from the dark-stable $\mathrm{S}_{1}$ state. The oxidation states of $\mathrm{Mn}$ are indicated in the order $\mathrm{Mn} 1, \mathrm{Mn} 2, \mathrm{Mn} 3, \mathrm{Mn} 4$ of the $\mathrm{Mn}_{4} \mathrm{CaO}_{5}$ its binding pocket. The structure of this complex catalytic site has been revealed by years of research employing EPR, EXAFS, and X-ray crystallography measurements, as well as theoretical calculations for recent contributions (e.g., Messinger et al. 1997; Peloquin et al. 2000; Zouni et al. 2001; Cinco et al. 2002; Robblee et al. 2002; Ferreira et al. 2004; Yano et al. 2006; Kulik et al. 2007; Dau and Haumann 2008; Siegbahn 2009; Umena et al. 2011; Glöckner et al. 2013; Shoji et al. 2013; Cox et al. 2014; Yano and Yachandra 2014; Krewald et al. 2015; Suga et al. 2015; Young et al. 2016). This pocket positions a network of hydrogen-bonded water molecules around the inorganic unit (Umena et al. 2011), thereby orchestrating the protoncoupled electron transfer events required for the accumulation of four oxidizing equivalents and the subsequent water oxidation chemistry (Lavergne and Junge 1993; Rappaport and Lavergne 1997; Dau and Haumann 2008; Service et al. 2010; Rappaport et al. 2011; Nakamura et al. 2016; Nilsson et al. 2016).

On the basis of the period four oscillation during flashinduced oxygen evolution, first measured by Joliot et al. (1969), and additional experiments, five oxidation states of the OEC were identified and named by Kok and coworkers as the $\mathrm{S}_{0}, \mathrm{~S}_{1}, \mathrm{~S}_{2}, \mathrm{~S}_{3}$, and $\mathrm{S}_{4}$ states (Fig. 1b) (Kok et al. 1970; Joliot and Kok 1975). For different, earlier proposals, see Joliot et al. (1969) and Mar and Govindjee (1972). Proton release occurs on all transitions, except the $S_{1} \rightarrow S_{2}$ transition

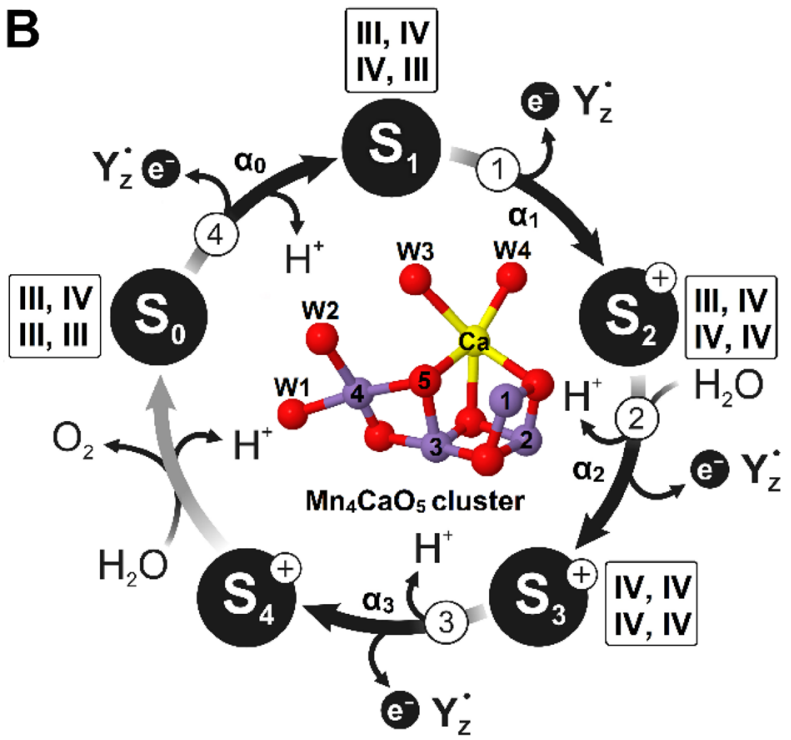

cluster, which is depicted in the center of the Kok cycle (see Kok et al. 1970). $\alpha_{i}$ signifies the miss parameter connected to the oxidation of the respective $S_{i}$ state $(i=0-4)$. Color code: $\mathrm{O}$ red, $\mathrm{Mn}$ purple, $\mathrm{Ca}$ yellow. W1-W4 are terminal water ligands (W2 may be a hydroxo) of Mn4 and Ca. The structures shown are based on pdb 5TIS (Young et al. 2016) 
(Rappaport and Lavergne 1991; Schlodder and Witt 1999). This is important, to allow $Y_{Z}{ }^{\bullet}$, which has a near constant oxidation potential throughout the reaction cycle, to stepwise oxidize the $\mathrm{Mn}_{4} \mathrm{CaO}_{5}$ cluster. Thus, in the positively charged $\mathrm{S}_{2}{ }^{+}$state, initially a proton needs to be released to allow oxidation of the neutral $\mathrm{S}_{2}{ }^{\mathrm{n}}$ state to the $\mathrm{S}_{3}{ }^{+}$state (Rappaport and Lavergne 1991; Klauss et al. 2012). This step is also likely coupled with the binding of one water molecule to the $\mathrm{Mn}_{4} \mathrm{CaO}_{5}$ cluster (Haumann et al. 2005; Suzuki et al. 2008; Siegbahn 2009; Suga et al. 2015, 2017; Capone et al. 2016; Retegan et al. 2016; Ugur et al. 2016; Kim and Debus 2017). Similarly, $S_{3}{ }^{n}$ state needs to be formed by a proton release from $\mathrm{S}_{3}{ }^{+}$before the OEC can be further oxidized and in turn form $\mathrm{O}_{2}$ from the two substrate 'water' molecules (Rappaport et al. 1994; Rappaport and Lavergne 2001; Dau and Haumann 2007; Klauss et al. 2015).

The most stable oxidation state of the OEC is the $S_{1}$ state, in which the four Mn ions have the oxidation states III, IV, IV, III; in the order of numbering in Fig. 1b (Krewald et al. 2015). The $S_{2}$ (III, IV, IV, IV) and $S_{3}$ (IV, IV, IV, IV) states decay to the $S_{1}$ state within seconds to minutes via reduction by the reduced form of tyrosine $Y_{\mathrm{D}}^{\mathrm{RED}}$ (D2-Tyr160) or recombination with $Q_{\mathrm{B}}{ }^{-}$(Diner 1977; Rutherford et al. 1982; Robinson and Crofts 1983; Rutherford and Inoue 1984; Vermaas et al. 1984, 1988; Nugent et al. 1987). In addition, a very slow decay was reported, but the electron donor for this phase was not yet identified (Styring and Rutherford 1988). By contrast, the $S_{0}$ state is slowly oxidized to the $\mathrm{S}_{1}$ state by the long-lived $Y_{\mathrm{D}}{ }^{\mathrm{OX}}$ radical, but is stable if $Y_{\mathrm{D}}$ is reduced (Styring and Rutherford 1987; Vass and Styring 1991; Messinger and Renger 1993). The highly reactive $S_{4}$ state oxidizes two water molecules into molecular oxygen. Through this process, four electrons are injected into the OEC, effectively resetting the system for the next cycle into the $\mathrm{S}_{0}$ state (III, IV, III, III).

The damping of the period four oscillation in flashinduced oxygen evolution shows that the $S_{i}$ state transitions do not occur with $100 \%$ efficiency. This inefficiency is described in the Kok model mostly by the miss parameter, which gives the average probability that an $S_{i}$ state does not advance, upon saturating flash illumination, into the next higher $\mathrm{S}_{\mathrm{i}+1}$ state (Forbush et al. 1971; Delrieu 1974; Messinger and Renger 2008). Typical values for the $\mathrm{S}_{\mathrm{i}}$-state-independent miss parameter range between 10 and 15\% (Messinger and Renger 1994; Isgandarova et al. 2003). Depending on the width of the exciting flash, typically also $0-5 \%$ of double advancements $\left(\mathrm{S}_{i}\right.$ to $\mathrm{S}_{i+2}$ transitions) contribute to the $\mathrm{S}$ state mixing with increasing flash number. Under saturating illumination, the miss parameter has been proposed to be governed by either the redox equilibria between the redox cofactors at the donor or acceptor sides, or by kinetic limitations (Renger and Hanssum 1988; Meunier and Popovic 1990; Shinkarev and Wraight 1993;
Christen et al. 1999; de Wijn and van Gorkom 2002; Han et al. 2012). To minimize the possibility of kinetic limitations, we employed in this study a flash frequency of $2 \mathrm{~Hz}$. In addition, we explicitly account for back reactions of the $\mathrm{S}$ states by our global fit analysis (Vass et al. 1990; Isgandarova et al. 2003; Pham and Messinger 2016). Thus, the efficiency of the $S_{i}$ state turnovers is expected to be governed by redox equilibria between all the electron transfer cofactors of PSII. These equilibria prevent, in a random fashion, a certain percentage of centers (miss parameter $\alpha$ ) from advancing to the next higher oxidation state $S_{i}(i=0,1,2,3,4)$ by preventing a stable charge separation. In this regard, especially the presence of $Q_{\mathrm{A}}^{-}, \mathrm{Pheo}^{-}, \mathrm{P} 680^{+}$, and/or $Y_{\mathrm{Z}}{ }^{\bullet}$ at the time of flash excitation is of note, which may vary with a period two on the acceptor side and a period four on the donor side (Naber et al. 1993; Shinkarev and Wraight 1993). In addition, inefficiencies of the $\mathrm{S}_{i}$ state transitions caused by deprotonation events (Forbush et al. 1971) or structural equilibria, as that in the $\mathrm{S}_{2}$ state between the EPR multiline and the $g=4.1$ state (Retegan et al. 2016), may lead to a $S_{i}$ state dependence of the miss parameter. Recent work by several groups provided experimental support for the $S_{i}$ state dependence of the miss parameter. While fluorescence experiments by de Wijn and van Gorkom (2002) and FTIR experiments by Takumi Noguchi's group (Suzuki et al. 2012) suggest that the miss parameters $\alpha_{i}$ increase from $\alpha_{0}$ to $\alpha_{3}$, Stenbjörn Styring and coworkers concluded on the basis of EPR experiments that the highest miss factor is associated with the $\mathrm{S}_{2} \rightarrow \mathrm{S}_{3}$ transition (Han et al. 2012). We have recently developed a new kinetic Kok model that allows fitting a regular $2 \mathrm{~Hz}$ flashinduced oxygen evolution pattern (FIOP) simultaneously with 44 FIOPs obtained during the $\mathrm{S}_{2^{-}}, \mathrm{S}_{3^{-}}$, and $\mathrm{S}_{0^{-}}$state lifetime measurements (Isgandarova et al. 2003; Pham and Messinger 2016). This global analysis, which works akin to decay-associated spectral analysis, indicated that the majority of misses occurs in spinach thylakoids at neutral $\mathrm{pH}$ in either the $S_{2} \rightarrow S_{3}$ or the $S_{3} \rightarrow S_{0}$ transition. In addition to misses, a small percentage of double hits $\left(\beta ; S_{i} \rightarrow S_{i+2}\right)$ is observed if light pulses of $\mu$ s duration are employed.

The extremophilic red alga Cyanidioschyzon merolae grows in hot springs at a very low $\mathrm{pH}(0.2-4.0)$ and moderately high temperatures $\left(40-56{ }^{\circ} \mathrm{C}\right)($ Ciniglia et al. 2004; Ferris et al. 2005). The intracellular $\mathrm{pH}$ of $C$. merolae is tightly controlled metabolically and maintained in the $\mathrm{pH}$ range of 6.3-7.1 over the extracellular $\mathrm{pH}$ range of 1.5-7.5 (Zenvirth et al. 1985; Enami et al. 2010). The photosynthetic apparatus of this alga is an evolutionary intermediate of cyanobacteria and higher eukaryotic phototrophs, containing combined prokaryotic and eukaryotic structural and functional features. Both PSII and PSI complexes from this acido-thermophilic alga are characterized by unprecedented robustness across a wide range of external conditions and recently molecular mechanisms underlying such resilience 
to adverse conditions have been revealed including reaction center-based non-photochemical quenching in PSII, accumulation of photoprotective carotenoid zeaxanthin (in PSII and PSI), and remodeling of the external light-harvesting antenna in PSI (Krupnik et al. 2013; Haniewicz et al. 2018).

The PSII complex in C. merolae is reminiscent of its counterpart in cyanobacteria, but the OEC is protected by the additional fourth extrinsic subunit PsbQ', over and above the three proteins present in cyanobacteria, PsbV, PsbU, and PsbO (Ohta et al. 2003). The PsbQ' subunit has been localized by electron microscopy coupled to single particle analysis (Krupnik et al. 2013) as well as recently by X-ray crystallography (Ago et al. 2016) on the lumenal side of PSII in the vicinity of the CP43 and PsbV proteins, close to the membrane plane. The function of PsbQ' has been recently elucidated by reconstitution of this protein with the cyanobacterial PSII followed by measurement of the $Q_{\mathrm{A}}$ redox potential in thus modified complex. In these experiments, the redox potential of $Q_{\mathrm{A}}$ was shown to be positively shifted when PsbQ' was attached to the PSII complex, likely resulting in a decrease in the amount of destructive triplet $\mathrm{Chl}$ species (Yamada et al. 2018) and triggering a photoprotective mechanism of direct recombination between $Q_{\mathrm{A}}{ }^{-}$and $\mathrm{P}_{680}+$ in high light (Krupnik et al. 2013).

On the acceptor side, the potential of $Q_{\mathrm{A}}{ }^{-} / Q_{\mathrm{A}}$ is significantly less negative in $C$. merolae $\left(E_{\mathrm{m}}=-104 \mathrm{mV}\right)$ than in spinach $\left(E_{\mathrm{m}}=-163 \mathrm{mV}\right)$ (Shibamoto et al. 2010). Given that the midpoint potentials of the other redox cofactors, including $Q_{\mathrm{B}}{ }^{-} / Q_{\mathrm{B}}, Q_{\mathrm{B}} \mathrm{H}_{2} / Q_{\mathrm{B}}{ }^{-}$and $\mathrm{Pheo}{ }^{-} / \mathrm{Pheo}$ are similar in these organisms (no comparable data available in the literature), the less negative $E_{\mathrm{m}}$ of $Q_{\mathrm{A}}{ }^{-} / Q_{\mathrm{A}}$ is expected to increase the $Q_{\mathrm{A}}{ }^{-}$population and thereby the miss parameter in comparison to spinach PSII centers. In addition, the larger energy gap between $\mathrm{Pheo}^{-} / \mathrm{Pheo}$ and $Q_{\mathrm{A}}{ }^{-} / Q_{\mathrm{A}}$ is expected to increase the lifetime of the $\mathrm{S}_{2}$ and $\mathrm{S}_{3}$ states in C. merolae PSII centers (Fig. 2). Interestingly, Allakhverdiev and coworkers reported a shift of redox potentials of $\mathrm{Q}_{\mathrm{A}}$ and Pheo depending on the presence or absence of extrinsic proteins in the cyanobacterial PSII complexes of Synechocystis sp. and Acaryochloris marina (Allakhverdiev et al. 2010, 2011). Yet, the energetics of the water-splitting reaction in PSII RC was conserved, even though the potentials of $Q_{\mathrm{A}}{ }^{-}$and $\mathrm{Pheo}^{-}$were relatively shifted depending on the identity of the primary donor special pair (being Chl $a$ in Synechocystis and $\mathrm{Chl} d$ in Acaryochloris), pointing towards high conservation of the electron transfer processes in oxygenic photosynthesis.

To analyze the effects of the altered $Q_{\mathrm{A}}{ }^{-} / Q_{\mathrm{A}}$ midpoint potential in detail and to separate it from $\mathrm{S}_{i}$-state-dependent effects, we measured flash-induced oxygen yield patterns of $C$. merolae thylakoids at three different $\mathrm{pH}$ values and after $\mathrm{H} / \mathrm{D}$ exchange, and analyzed the data using our global fit analysis approach. High $\mathrm{pH}$ is expected to simplify

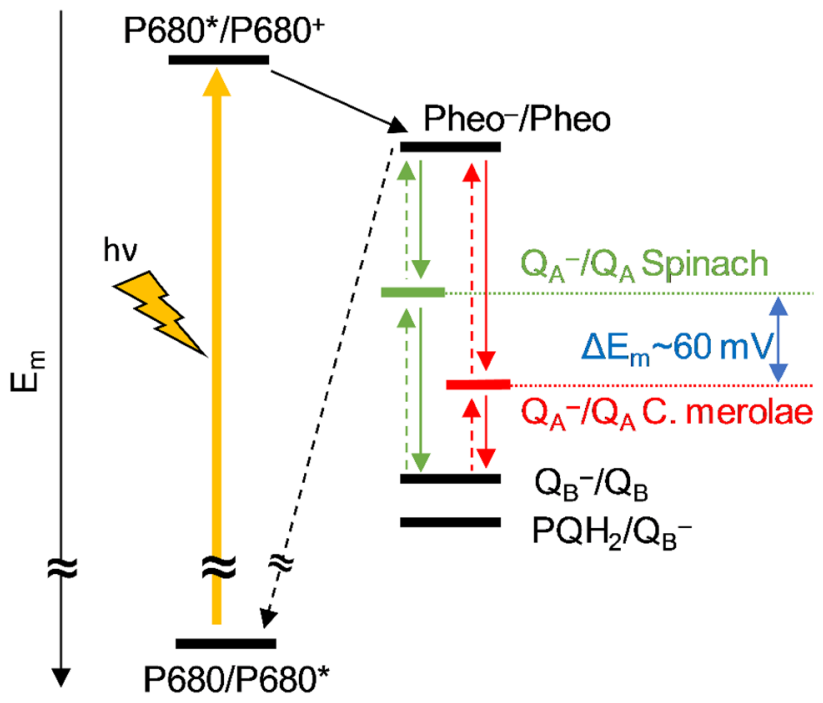

Fig. 2 Schematic representation (not to scale) of midpoint potentials on the acceptor side of PSII in $C$. merolae and spinach. The focus is on the $E_{\mathrm{m}}$ values of $Q_{\mathrm{A}}{ }^{-} / Q_{\mathrm{A}}$ in both organisms, since a direct comparison has been made in one study (Shibamoto et al. 2010). We emphasize that the $E_{\mathrm{m}}$ values of the other components may also differ between the two organisms, but no comparative data were found

deprotonation reactions needed to advance the $\mathrm{Mn}_{4} \mathrm{CaO}_{5}$ cluster into the next $\mathrm{S}_{i}$ state and to thereby reduce the donor side misses. It may also be expected that high $\mathrm{pH}$ makes it more difficult to protonate $Q_{\mathrm{B}}{ }^{2-} / Q_{\mathrm{B}}{ }^{-}$. This, in turn, may increase their midpoint potentials, likely leading to increased acceptor side misses. The results obtained in the present study are compared to literature data for spinach thylakoids measured under similar conditions.

\section{Materials and methods}

\section{Thylakoid preparation}

Cyanidioschyzon merolae cells were cultured at $42{ }^{\circ} \mathrm{C}$ and the thylakoids were isolated as described by (Krupnik et al. 2013), frozen in liquid nitrogen and stored at $-80^{\circ} \mathrm{C}$ until used. On the day of the FIOP experiments, the thylakoids were thawed in the dark on ice and washed three times with buffer containing $10 \mathrm{mM} \mathrm{CaCl}_{2}, 5 \mathrm{mM} \mathrm{MgCl}_{2}, 1 \mathrm{M}$ betaine, and either $40 \mathrm{mM}$ succinic acid/ $\mathrm{NaOH}$ (pH 5.0), $40 \mathrm{mM}$ MES/NaOH (pH 6.1), or $40 \mathrm{mM}$ HEPES/NaOH ( $\mathrm{pH}$ 8.0). In the case of $\mathrm{D}_{2} \mathrm{O}$ experiments, the buffer was prepared in $99.9 \% \mathrm{D}_{2} \mathrm{O}$ at $40 \mathrm{mM} \mathrm{MES} / \mathrm{NaOD}$ (pD 6.1). In the last step, the samples were diluted to $[\mathrm{Chl}]=0.5 \mathrm{mg} / \mathrm{ml}$. After this treatment, which required $\sim 10 \mathrm{~min}$, the relative flash-induced $\mathrm{O}_{2}$ yields were $25 \%(\mathrm{pH} 5.0), 100 \%$ ( $\mathrm{pH} 6.1$ ), and $45 \%$ (pH 8.0). No further decline in the activity was observed during the experiments. The $C$. merolae thylakoid 
sample had a small population of $Y_{\mathrm{D}}^{\mathrm{RED}}(\approx 10 \%)$. Therefore, the dark-adapted thylakoid sample was used without preflash treatment.

\section{FIOPs and $S_{i}$-state lifetime measurements}

The FIOP measurements on C. merolae thylakoids were performed with an unmodulated home-built Joliot-type electrode at $20^{\circ} \mathrm{C}$ without adding artificial electron acceptors (Joliot 1972; Messinger and Renger 1993). Stock solutions of catalase from bovine liver (3809 U/mg, Sigma-Aldrich) were prepared by dissolving the frozen catalase powder in the respective measuring buffer. The catalase concentrations were determined using the Bradford assay (Bradford 1976; Sedmak and Grossberg 1977) and the enzymatic activities were measured using Beers assay (Beers and Sizer 1952; Aebi 1984). Then, $10,000 \mathrm{U} / \mathrm{ml}$ catalase was added into the thylakoid samples and the mixture was incubated for $10 \mathrm{~min}$. In addition, the measuring buffer in the reservoir of the Joliot-electrode was continuously bubbled with $\mathrm{N}_{2}$ to remove $\mathrm{O}_{2}$ and prevent electrochemical formation of $\mathrm{H}_{2} \mathrm{O}_{2}$ during measurements (Pham and Messinger 2014).

For each FIOP, a fresh 10- $\mu$ l aliquot of the thylakoid sample was transferred to the surface of a bare Pt-cathode in dim green light and the sample was incubated for $3 \mathrm{~min}$ on the electrode to allow for settling and temperature adaptation. The polarization voltage of $-750 \mathrm{mV}$ was switched on $40 \mathrm{~s}$ before illuminating the sample with a series of 16 flashes (2 Hz; Perkin Elmer, LS-1130-4 flash lamp). A personal computer was employed to trigger the flash lamp and to record the data at a sampling rate of 3600 points/s. The $\mathrm{S}_{2^{-}}, \mathrm{S}_{3^{-}}$, and $\mathrm{S}_{0^{-}}$state lifetimes of thylakoid samples were measured in the same way by exciting dark-adapted samples with one ( $S_{2}$ state formation), two $\left(S_{3}\right.$ state formation), or three $\left(\mathrm{S}_{0}\right.$ state formation) pre-flash(es) while resting on the electrode surface. After the desired dark time $\left(t_{\mathrm{d}}\right)$, a series of 16 flashes $(2 \mathrm{~Hz})$ was applied. The polarization was always applied $40 \mathrm{~s}$ before the flash series.

\section{Data analysis of FIOPs}

For each FIOP, 16 oxygen yields were recorded. However, only the first 8 flash-induced oxygen yields were used for data analysis since thereafter, a strong decline of the $\mathrm{O}_{2}$ yield was observed (Fig. 3). In the global fitting approach, 384 flash-induced oxygen yields comprising all time points of the $S_{2}, S_{3}$, and $S_{0}$ lifetime measurements were directly and simultaneously fitted by adjusting the rate constants of all $\mathrm{S}_{i}$ state decays, the $\mathrm{S}_{i}$-state-dependent miss parameters, the double-hit probability, the activity/damping parameter, and the initial percentages of $\mathrm{S}_{i}$ states, $Y_{\mathrm{D}}$ and $Q_{\mathrm{B}}{ }^{-}$(Pham and Messinger 2016).

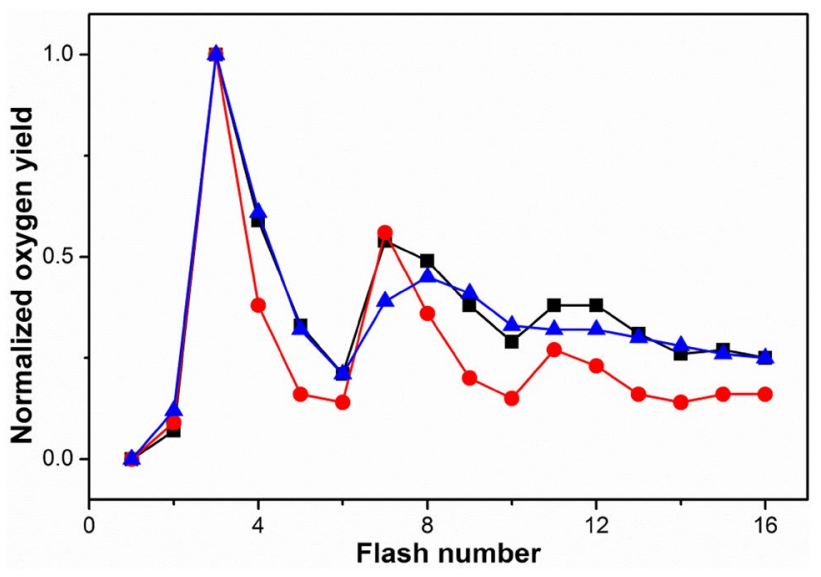

Fig. 3 FIOPs of dark-adapted C. merolae thylakoids obtained at $20{ }^{\circ} \mathrm{C}$ and $\mathrm{pH} 5.0$ (black squares), 6.1 (red dots), or $\mathrm{pH} 8.0$ (blue triangles). The data were normalized to the oxygen yield induced by the 3rd flash. The flash frequency was $2 \mathrm{~Hz}$

\section{Results and discussion}

The flash-induced oxygen evolution patterns (FIOPs) and the $\mathrm{S}_{i}$-state lifetime measurements of $C$. merolae thylakoids were recorded at $\mathrm{pH}$ 5.0, 6.1, and 8.0 with a Joliot-type bare platinum electrode (Isgandarova et al. 2003). The results are presented in Figs. 3 and 4, as well as in Tables 1 and 2.

\section{$\mathrm{pH}$ dependence of the miss parameters}

Since the thylakoid preparation of $C$. merolae contained only about $10 \%$ of reduced $Y_{D}$, the FIOPs shown in Fig. 3 can be discussed qualitatively without considering the back reactions in the dark periods of $500 \mathrm{~ms}$ between the flashes. At $\mathrm{pH}$ 6.1, a clear period four oscillation with maxima after the 3rd, 7th, and 11th flash was seen, indicating a low average miss parameter (red spheres in Fig. 3). The overall amplitude of the 3rd oscillation (flashes 11 and onwards) was, however, untypically low. This FIOP was reminiscent to that of spinach BBY preparations, indicating a limited pool of plastoquinone bound on the acceptor side of $C$. merolae PSII complex embedded in thylakoid membrane fragments.

After transferring the thylakoid samples to $\mathrm{pH}$ 5, a FIOP with a clearly increased miss parameter was obtained (black squares in Fig. 3). This was visible by the decreased ratio of the $\mathrm{O}_{2}$ yields induced by the 3 rd flash $\left(\mathrm{Y}_{3}\right)$ to that of the 4th flash $\left(\mathrm{Y}_{4}\right)$. Similarly, the ratios $\mathrm{Y}_{7} / \mathrm{Y}_{8}$ and $\mathrm{Y}_{11} / \mathrm{Y}_{12}$ were diminished compared to those obtained at $\mathrm{pH}$ 6.1. Interestingly, the average $\mathrm{O}_{2}$ yield per flash obtained at higher flash numbers did not decrease to the same extent as at $\mathrm{pH}$ 6.1. This can be explained by the finding that the total $\mathrm{O}_{2}$ yield was only about $25 \%$ of that at neutral $\mathrm{pH}$. The reduced number of active PSII complexes thus increased the number of plastoquinone molecules available for the active PSII 


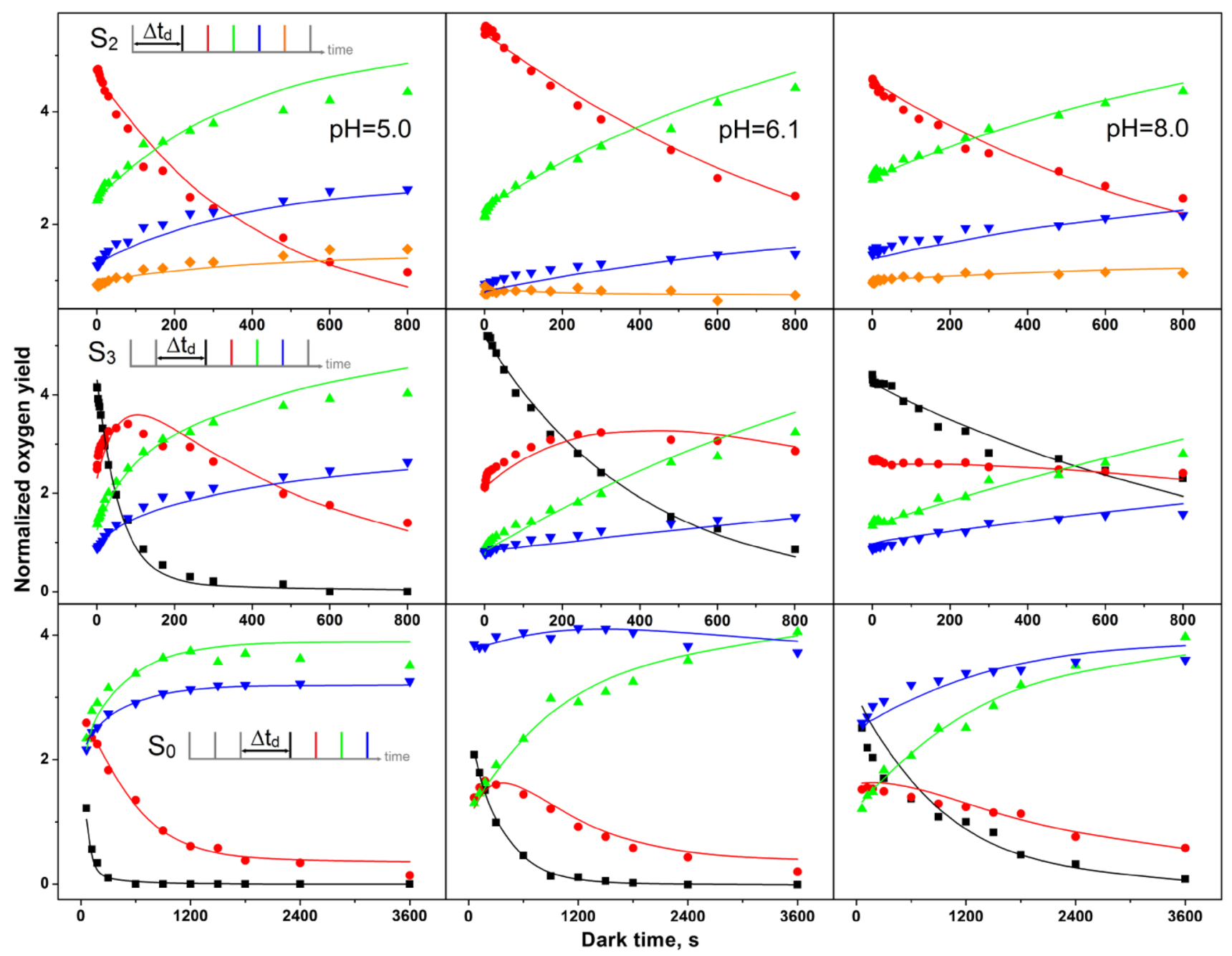

Fig. $4 \mathrm{~S}_{2^{-}}, \mathrm{S}_{3^{-}}$, and $\mathrm{S}_{0^{-}}$-state lifetime measurements at $\mathrm{pH}$ 5.0, $\mathrm{pH} 6.1$, and 8.0. The normalized flash-induced oxygen yields of flashes 2-5 $\left(\mathrm{S}_{2}\right)$ or 1-4 $\left(\mathrm{S}_{3}, \mathrm{~S}_{0}\right)$ are plotted as a function of dark time between the pre-flash(es) and the flash train. The color code is given in the respec- tive inserts. Symbols are the experimental amplitudes, while the lines connect the amplitudes calculated by the global fitting program. Rate constants are given in Table 1 , unequal miss fit complexes. The strong decline in the number of active PSII centers in thylakoids of $C$. merolae was surprising, since a recent report showed that the $\mathrm{O}_{2}$ rates of PSII core complexes isolated from the same organism are nearly invariant between pH 5.0 and 8.0 (Krupnik et al. 2013).

Comparison of the FIOP obtained at $\mathrm{pH} 8.0$ (blue triangles in Fig. 3) and pH 5.0 showed that while the first 6 normalized $\mathrm{O}_{2}$ yields were nearly identical, clear deviations were seen thereafter. Specifically, the $\mathrm{Y}_{7} / \mathrm{Y}_{8}$ ratio was inverted. This was indicative of a significantly different flash number or $\mathrm{S}_{i}$ state dependence of the miss parameters at these two $\mathrm{pH}$ values. The total $\mathrm{O}_{2}$ yield was about $45 \%$ at $\mathrm{pH} 8.0$ as compared to $\mathrm{pH} 6.1$. This again resulted in a larger plastoquinone pool per active PSII complex.

The global fit program (GFP) analysis confirms these qualitative observations. Table 1 compares the best-fit parameters obtained at each $\mathrm{pH}$ by either enforcing equal misses or by allowing the miss parameter to be different for each $\mathrm{S}_{\mathrm{i}}$ state transition. At $\mathrm{pH}$ 6.1, an equal miss fit results in a miss parameter $\alpha$ of about $11 \%$, while in the best $\mathrm{S}_{\mathrm{i}}$-state-dependent miss fit, all misses (35\%) occur in the $S_{2} \rightarrow S_{3}$ transition. Importantly, the fit quality of the unequal miss fit is twice as good as that of the equal miss fit, strongly favoring the fit where $\alpha_{2}$ parameter is largest. This is further supported by the finding that this fit result is systematically found once the equal miss constraint is released. However, when fits were started with a high value for $\alpha_{1}$ or $\alpha_{3}$ (all other $\alpha_{i}=0$ ), stable solutions were obtained with $35 \%$ miss in the respective $S_{i}$ state transition. The fit qualities $\left(F_{\mathrm{Q}}\right)$ of these fits were in between the best fit and the equal miss fit (Table 2). Nevertheless, as soon as a few percent $\alpha_{2}$ was included into the starting 
Table 1 Fit parameters obtained during a global fit of a $2 \mathrm{~Hz}$ FIOP and $\mathrm{S}_{3}, \mathrm{~S}_{2}$, and $\mathrm{S}_{0}$ lifetime measurements of $C$. merolae thylakoids at $20^{\circ} \mathrm{C}$ and the indicated $\mathrm{pH}$ values

\begin{tabular}{lllllll}
\hline & Equal miss & & & \multicolumn{2}{l}{$\mathrm{S}_{i}$-state-dependent miss (best fit) } \\
\hline $\mathrm{pH}$ & 5.0 & 6.1 & 8.0 & 5.0 & 6.1 & 8.0 \\
$\alpha_{0}, \%$ & 18 & 11 & 22 & 0 & 0 & 40 \\
$\alpha_{1}, \%$ & 18 & 11 & 22 & 0 & 0 & 0 \\
$\alpha_{2}, \%$ & 18 & 11 & 22 & 54 & 35 & 48 \\
$\alpha_{3}, \%$ & 18 & 11 & 22 & 0 & 0 & 6 \\
$\beta, \%$ & 1.6 & 3.8 & 3.8 & 1.6 & 2.5 & 2.7 \\
$\mathrm{~d}, \%$ & 98 & 96 & 96 & 97 & 95 & 98 \\
$k_{32 \text { (fast) }}, \mathrm{s}^{-1}$ & $2.0^{\mathrm{a}}$ & 1.5 & 0.028 & 3.2 & 0.32 & 4.4 \\
$\mathrm{k}_{32 \text { (slow) }}, \mathrm{s}^{-1}$ & 0.0172 & 0.0030 & 0.0012 & 0.0165 & 0.0029 & 0.0012 \\
$k_{21 \text { (fast) }}, \mathrm{s}^{-1}$ & 1.4 & 2.1 & 0.07 & 0.8 & 1.4 & 2.4 \\
$k_{21 \text { (slow) }}, \mathrm{s}^{-1}$ & 0.0030 & 0.0015 & 0.0014 & 0.0022 & 0.0012 & 0.0012 \\
$\mathrm{k}_{01}, \mathrm{~s}^{-1}$ & 2.3 & 0.0004 & 0.00007 & 2.0 & 0.00020 & 0.035 \\
${\text { Fit quality }\left(* 10^{-8} \text { ) }\right.}$ & 1625 & 970 & 600 & 615 & 495 & 362 \\
\hline
\end{tabular}

Fits assuming either $S_{i}$-state-independent (equal) or $S_{i}$-state-dependent (unequal) miss probabilities are presented. Parameters: $\alpha_{i}$, miss parameter connected to the oxidation of the $S_{i}$ state $(i=0-4) ; \beta$ double-hit parameter; d, damping/activity parameter; $\mathrm{k}_{32}, \mathrm{k}_{21}$, and $\mathrm{k}_{01}$, rate constants of $\mathrm{S}_{3}, \mathrm{~S}_{2}$, and $\mathrm{S}_{0}$ decay to the $S_{1}$ state. All fits are based on the following properties of the dark-adapted sample: $100 \% S_{1}$ state population, $Y_{\mathrm{D}}=10 \%$. A smaller value for the fit quality indicates a better fit. For further details see (Pham and Messinger 2016)

${ }^{a}$ Rates for the fast $\mathrm{S}_{2}$ and $\mathrm{S}_{3}$ decay, as well as for $\mathrm{S}_{0}$ oxidation are less reliable due to the small $Y_{\mathrm{D}}$ population giving insufficient constraints for fitting the fast $S_{2}$ and $S_{3}$ decays; they are thus displayed in italics

\begin{tabular}{llllllll}
\hline $\mathrm{pH}$ & 5.0 & 5.0 & 6.1 & 6.1 & 8.0 & 8.0 & 8.0 \\
$\alpha_{0}, \%$ & 0 & 0 & 0 & 0 & 0 & 0 & 43 \\
$\alpha_{1}, \%$ & 0 & 54 & 0 & 35 & 0 & 0 & 0 \\
$\alpha_{2}, \%$ & 0 & 0 & 0 & 0 & 57 & 47 & 0 \\
$\alpha_{3}, \%$ & 54 & 0 & 35 & 0 & 0 & 20 & 51 \\
$\beta, \%$ & 1.6 & 1.6 & 2.9 & 2.9 & 1.4 & 2.1 & 3.1 \\
$\mathrm{~d}, \%$ & 97 & 98 & 95 & 95 & 95 & 95 & 98 \\
$k_{32 \text { (fast) }}, \mathrm{s}^{-1}$ & $2.5^{\mathrm{a}}$ & 1.8 & 0.15 & 0.33 & 0.017 & 0.023 & 6.9 \\
$\mathrm{k}_{32 \text { (slow) }}, \mathrm{s}^{-1}$ & 0.016 & 0.011 & 0.0029 & 0.0027 & 0.0012 & 0.0011 & 0.0012 \\
$k_{21 \text { (fast }}, \mathrm{s}^{-1}$ & $0.0024^{*}$ & 0.0037 & 1.2 & 1.5 & 2.3 & 0.028 & $10^{*}$ \\
$\mathrm{k}_{21 \text { (slow) }}, \mathrm{s}^{-1}$ & 0.0024 & 0.0037 & 0.0013 & 0.0016 & 0.0011 & 0.0011 & 0.0015 \\
$k_{01}, \mathrm{~s}^{-1}$ & 2.0 & 2.0 & 0.00020 & 0.00016 & 0.00009 & 0.00090 & 0.01200 \\
Fit quality $\left(\times 10^{-8}\right)$ & 675 & 1330 & 536 & 645 & 890 & 600 & 610 \\
\hline
\end{tabular}

The asterisk indicates that a parameter was constrained

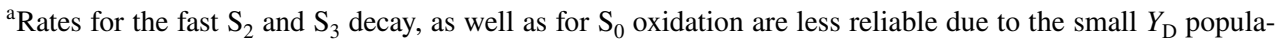
tion giving insufficient constraints for fitting the fast $S_{2}$ and $S_{3}$ decays; they are thus displayed in italics
Table 2 Alternative fit parameters obtained during a global fit of a $2 \mathrm{~Hz}$ FIOP and $\mathrm{S}_{3}, \mathrm{~S}_{2}$, and $\mathrm{S}_{0}$ lifetime measurements of $C$. merolae thylakoids at $20^{\circ} \mathrm{C}$ and indicated $\mathrm{pH}$ values conditions, the GFP finds the solution where $\alpha_{2}=35 \%$. Forcing most misses into $\alpha_{0}$ resulted in unsatisfactory fits.

The finding that only one $\mathrm{S}$ state transition is responsible for all misses, whereas the other transitions occur at $100 \%$ efficiency, is counterintuitive and may be explained by shallow fit minima. Increasing manually the percentages of misses in other transitions demonstrates that the fit quality deteriorates by less than $15 \%$ if either $\alpha 1$ or $\alpha 3$ is increased up to $5 \%$ at the expense of $\alpha 2$. In contrast, redistributing $10 \%$ miss from $\alpha 2$ to $\alpha 1$ or $\alpha 3$, individually or combined, or increasing $\alpha 0$ by only $3 \%$ leads to a $40 \%$ worsening of the fit quality.

The fits for the pH 5.0 FIOP show the identical trends, except that the misses were higher: $18 \%$ for equal miss fits and $54 \%$ for the $\mathrm{S}_{2} \rightarrow \mathrm{S}_{3}$ transition (Table 1). At this $\mathrm{pH}$ value, the unequal miss fit was nearly three times better compared to the equal miss fit. The fit where $\alpha_{3}$ is dominating has a nearly as good $F_{\mathrm{Q}}$ as the one with $\alpha_{2}=54 \%$; however, the value of $\mathrm{k}_{21 \text { (fast) }}$ equals $\mathrm{k}_{21 \text { (slow), }}$, i.e., it was hitting the lower fit limit (Tables 1,2). The fit where $\alpha_{1}$ 
is forced to be maximum, results in a fit that is nearly as poor as the equal miss fit. The large difference between the equal and $\mathrm{S}_{i}$-state-dependent miss approaches comes from the-relative to $\mathrm{Y}_{3} / \mathrm{Y}_{4}$ - large $\mathrm{Y}_{7} / \mathrm{Y}_{8}$ ratio, which can only be modeled correctly with unequal misses, where $\alpha_{2}$ or $\alpha_{3}$ dominates.

In contrast to $\mathrm{pH} 5.0$ and 6.1, the FIOP obtained at $\mathrm{pH}$ 8.0 could not be fitted well when we assumed that all the misses occur in the $\mathrm{S}_{2} \rightarrow \mathrm{S}_{3}$ transition or the $\mathrm{S}_{3} \rightarrow \mathrm{S}_{0}$ transition (Tables 1,2). For $\mathrm{pH} 8.0$, an almost equally large percentage of misses occurred in the $S_{0} \rightarrow S_{1}$ transition. Several good fits were also found where in addition to $\alpha_{0}$ and $\alpha_{2}$ also 5-20\% $\alpha_{1}$ or $\alpha_{3}$ were included.

Therefore, the quantitative GFP analysis of the $C$. merolae FIOPs obtained at three different $\mathrm{pH}$ values strongly supports unequal misses, whereby the majority of the misses occur in the $\mathrm{S}_{2} \rightarrow \mathrm{S}_{3}$ or, less likely, in the $\mathrm{S}_{3} \rightarrow \mathrm{S}_{0}$ transition at acidic and neutral $\mathrm{pH}$, while at alkaline $\mathrm{pH}$ the $\mathrm{S}_{0} \rightarrow \mathrm{S}_{1}$ transition becomes also inefficient. If proton release was the limiting factor for the efficiency of a $S_{i}$ state transition, one would expect the miss probability to decrease with increasing $\mathrm{pH}$. While this trend was observed for $\alpha_{2}$ when comparing $\mathrm{pH} 5.0$ and 6.1, this trend was not detected at $\mathrm{pH}$ 8.0.

Importantly, no binary oscillation of the miss parameter with the flash number $\left(\mathrm{S}_{i}\right.$ state) was found when analyzing the $\mathrm{pH} 5.0$ and 6.1 data. This supports the above analysis, which relied on the assumption that the contributions of the donor side dominate the miss parameter, while effects of the acceptor on the miss parameter are negligible.

In contrast, a pronounced binary oscillation of the miss parameter was observed at $\mathrm{pH}$ 8.0. This may be explained either by a high $\alpha_{0}$ and $\alpha_{2}$ or by high miss parameter connected to the presence of $\left(Q_{\mathrm{A}} Q_{\mathrm{B}}\right)^{-}$on the acceptor side (Naber et al. 1993; Shinkarev and Wraight 1993).

The pH jump experiments by Zaharieva et al. (2011) with spinach PSII membrane fragments, found effective $\mathrm{pK}$ values of 3.3, 3.5, and 4.6 for the inhibition of the $S_{1} \rightarrow S_{2}$, $\mathrm{S}_{2} \rightarrow \mathrm{S}_{3}$, and $\mathrm{S}_{3} \rightarrow \mathrm{S}_{0}$ transitions at low $\mathrm{pH}$, respectively. In contrast, none of the transitions showed decreased efficiencies at alkaline $\mathrm{pH}$ values. Furthermore, the $\mathrm{S}_{0} \rightarrow \mathrm{S}_{1}$ transition was found to be $\mathrm{pH}$ independent between $\mathrm{pH} 3$ and 9 . On that basis, one would expect that the $\mathrm{S}_{3} \rightarrow \mathrm{S}_{0}$ transition should be the only one affected by the $\mathrm{pH}$ under our experimental conditions. However, while the fits with large $\alpha_{3}$ generally gave acceptable results, they were consistently inferior to those with large $\alpha_{2}$. We thus suggest that the different time scales of incubation at the indicated $\mathrm{pH}, 1.5 \mathrm{~s}$. vs $>10 \mathrm{~min}$., are responsible for the deviating results. We also note that Zaharieva et al. (2011) observed relative changes in the efficiency of a specific $\mathrm{S}_{i}$ state transition caused by $\mathrm{pH}$ changes, not in the absolute $\alpha_{i}$ values, and that $\mathrm{pH}$ effects on the acceptor side are minimized in that study by giving only one flash at the desired $\mathrm{pH}$ value.
Our preferred assignment for the acidic to neutral $\mathrm{pH}$ $\left(\alpha_{2}>>\alpha_{3}, \alpha_{1}, \alpha_{0}\right)$ agrees well with the results of Han et al. (2012) who reported a similar trend by following the $S_{i}$ state populations during a flash train via $S_{i}$-state-specific EPR signals. A high $\alpha_{2}$ may be consistent with the proposed need of PSII samples in the $S_{2}$ multiline ('open cube') configuration to first convert into the $S_{2} g=4.1$ state ('closed cube') configuration, before they can reach the $S_{3}$ state (Retegan et al. 2016). Other possible explanations for why the highest miss parameter is connected to the $S_{2} \rightarrow S_{3}$ transition may include the need to bind one additional substrate (possibly in the form of hydroxide) and the small driving force for this transition (Suzuki et al. 2008; Cox et al. 2014; Kim and Debus 2017).

The increase of the miss probability of the $\mathrm{S}_{0} \rightarrow \mathrm{S}_{1}$ and $\mathrm{S}_{2} \rightarrow \mathrm{S}_{3}$ transitions in the alkaline $\mathrm{pH}$ cannot be easily explained by any of the above proposals, unless a second independent counter effect is brought into play. Since no artificial electron acceptors were used in this study, the period of two oscillations of the miss parameter may be taken as indication that the protonation of $\mathrm{Q}_{\mathrm{B}}{ }^{2-}$ became a limiting factor between $\mathrm{pH} 7$ and 8 , or that the $Q_{\mathrm{A}}{ }^{-} / Q_{\mathrm{A}}$ or $Q_{\mathrm{B}}{ }^{-} / Q_{\mathrm{B}}$ midpoint potentials get more similar under these conditions, leading to a high $Q_{\mathrm{A}}{ }^{-}$population on every second flash. Further studies will be necessary to untangle the $C$. merolae PSII donor and acceptor side contributions at alkaline $\mathrm{pH}$.

\section{pH dependence of $S_{i}$-state lifetimes}

For $\mathrm{S}_{i}$-state lifetime experiments, the dark-adapted thylakoid sample ( $S_{1}$ state) was excited by 1, 2, or 3 flashes to enrich PSII in the $S_{2}, S_{3}$, or $S_{0}$ state, respectively. Then, the dark time, $t_{\mathrm{d}}$, to the subsequent FIOP flash train $(2 \mathrm{~Hz})$ was varied in suitable steps to probe the fast and slow decay components (see insets in Fig. 4). The symbols in Fig. 4 show how the experimental flash-induced $\mathrm{O}_{2}$ yields varied as a function of $t_{d}$ during the three lifetime measurements. Plotted are either the $\mathrm{O}_{2}$-yields induced by flashes two to five $\left(\mathrm{Y}_{2}-\mathrm{Y}_{5}\right.$; $\mathrm{S}_{2}$ state decay) or $\mathrm{Y}_{1}-\mathrm{Y}_{4}\left(\mathrm{~S}_{3}\right.$ and $\mathrm{S}_{0}$ state decay). The $\mathrm{S}_{2}$ population can be qualitatively followed by the decay of $\mathrm{Y}_{2}$ (red dots), while $\mathrm{Y}_{1}$ tracks the $\mathrm{S}_{3}$ state population (black squares). The changes in the $S_{1}$ and $S_{0}$ populations can be estimated by amplitude changes of $\mathrm{Y}_{3}$ (green triangles) and $\mathrm{Y}_{4}$ (blue inverted triangles), respectively.

In the top row of Fig. 4, the $\mathrm{pH}$ dependence of the reaction $\mathrm{S}_{2} \rightarrow \mathrm{S}_{1}$ was studied. The simultaneous decay of $\mathrm{Y}_{2}$ and the corresponding rise of $\mathrm{Y}_{3}$ demonstrated for all three $\mathrm{pH}$ values a clean one-electron reduction process. Due to misses and double hits, a small rise of $Y_{4}$ and $Y_{5}$ was also observed. Only a very small fast phase was discernible, which was followed by one slower kinetic phase. While there were not enough points for the fast phase to reliably analyze its $\mathrm{pH}$ dependence, it could be observed that the slow phase of $\mathrm{S}_{2}$ 
decay was about 2-3-fold faster at $\mathrm{pH} 5.0$ than at the two other $\mathrm{pH}$ values.

The $\mathrm{pH}$ dependence of the $\mathrm{S}_{3}$ decay is best followed by the data presented in the central row. Due to the rapid $S_{3}$ decay at $\mathrm{pH}$ 5.0, the sequential decay of $\mathrm{S}_{3}\left(\mathrm{Y}_{1}\right) \rightarrow \mathrm{S}_{2}\left(\mathrm{Y}_{2}\right) \rightarrow \mathrm{S}_{1}\left(\mathrm{Y}_{3}\right)$ could be clearly discerned. $\mathrm{Y}_{4}$ increased nearly in parallel to $\mathrm{Y}_{3}$ due to misses. For the $\mathrm{S}_{3}$ decay, a strong retardation of the slow decay was observed at the higher $\mathrm{pH}$ values. For the $\mathrm{S}_{0} \rightarrow \mathrm{S}_{1}$ reaction, a qualitative analysis was complicated, as the expected decrease of $\mathrm{Y}_{4}$ was compensated by the contribution of $\mathrm{O}_{2}$ to $\mathrm{Y}_{4}$, which comes from centers in the $\mathrm{S}_{1}$ state that due to $\alpha 1$ are delayed by one flash in $\mathrm{O}_{2}$ production. This time-dependent increase in the $S_{1}$ state population is caused by $S_{0}$ oxidation and by back reactions from the $S_{3}$ and $S_{2}$ states. In addition, the increasing $Y_{D}$ population further increases $\mathrm{Y}_{4}$ by fast reduction of fractions of $\mathrm{S}_{2}$ and $\mathrm{S}_{3}$ between the flashes of the FIOP. Nevertheless, it appears that the $\mathrm{S}_{0}$ oxidation exhibits a complicated $\mathrm{pH}$ dependence in the $C$. merolae PSII complex, with the slowest rate near neutral $\mathrm{pH}$. To our knowledge, no previous data for the $\mathrm{S}_{0} \rightarrow \mathrm{S}_{1}$ reaction had been published at $\mathrm{pH} 5$ or $\mathrm{pH} 8$.

The lines in Fig. 4 connect the amplitudes calculated by the GFP using the parameters given in Table 1 for the best fits. Overall, despite some small deviations, a satisfactory agreement with the data were achieved. The fits confirm the trends discussed above for the slow $\mathrm{S}_{2}$ and $\mathrm{S}_{3}$ state decays at the three $\mathrm{pH}$ values studied. While the $\mathrm{S}_{2}$ state decay is nearly $\mathrm{pH}$ independent (within a factor of 2), the rate of $\mathrm{S}_{3}$ decay slowed by more than a factor of 10 between $\mathrm{pH} 5$ and 8. This is consistent with the previous data obtained from spinach thylakoids (Messinger and Renger 1994).

The most surprising finding is the very strong $\mathrm{pH}$ dependence of the rates for the $S_{0} \rightarrow S_{1}$ transition. While the rate at $\mathrm{pH} 6.1$ was well reproduced under all tested fit conditions and agreed within a factor of four with previous estimates in spinach thylakoids (Messinger and Renger 1994) and was practically identical with that determined with $T$. elongatus thylakoids (Messinger and Renger 1994; Isgandarova et al. 2003), the much faster oxidation rates at $\mathrm{pH} 5$ and 8 were surprising. Since in the present experiments we were unable to obtain strong constraints for the fast decay kinetics, the values for $k_{01}$ varied at the two extreme $\mathrm{pH}$ values quite considerably depending on the fit scenario. At $\mathrm{pH}$ 5.0, values between 0.21 and $2.7 \mathrm{~s}^{-1}$ were obtained, while $k_{01}$ was found to be in the range of 0.00007 and $0.035 \mathrm{~s}^{-1}$ at $\mathrm{pH} 8.0$. Thus, further studies are needed to determine the precise extent of the destabilization of $\mathrm{S}_{0}$ at $\mathrm{pH} 5.0$ and 8.0. Possible reasons for the faster $S_{0}$ oxidation could be related to the described two different positions of a water molecule near $Y_{\mathrm{D}}$ that appear to influence the redox potential of $Y_{\mathrm{D}} / Y_{\mathrm{D}}$ OX (Umena et al. 2011; Saito et al. 2013; Sjöholm et al. 2017), and other pathways for $S_{0}$ to $S_{1}$ conversion may be possible under extreme $\mathrm{pH}$ conditions. At alkaline $\mathrm{pH}$, also the easier removal of a proton may increase the rate of its conversion, since the $S_{0} \rightarrow S_{1}$ transition is coupled to a proton release (Rappaport and Lavergne 1991; Siegbahn 2013; Klauss et al. 2015).

\section{Effects of $H / D$ exchange}

To further understand the above $\mathrm{pH}$ effects, we performed a complete GFP analysis after H/D exchange at pD 6.1 (Table 3; Fig. 5). The data in Table 3 reveal that nearly all the fit parameters are identical under $\mathrm{H}_{2} \mathrm{O}$ and $\mathrm{D}_{2} \mathrm{O}$. However, there is a twofold increase in the rate of $\mathrm{S}_{3} Q_{\mathrm{B}}{ }^{-}$decay $\left[k_{32 \text { (slow) }}\right]$ and a sixfold increase of the rate in $\mathrm{S}_{0}$ oxidation to $\mathrm{S}_{1}$. In addition, a very small increase of $\alpha_{2}$ from 35 to $37 \%$ was observed. The slightly higher value of $\alpha_{2}$ in $\mathrm{D}_{2} \mathrm{O}$ is in line with the idea that a proton release during the $S_{2} \rightarrow S_{3}$ transition is required, since a slowdown of that rate due to the greater O-D bond strength will increase the miss parameter by increasing recombination reactions between $Q_{\mathrm{A}}{ }^{-}$and $Y_{\mathrm{Z}}^{\mathrm{OX}}$ (Zaharieva et al. 2011). However, the small magnitude of this effect indicates that this can only be one of the several factors contributing to the low efficiency of this transition.

Similarly, the acceleration of the slow $\mathrm{S}_{3}$ decay in $\mathrm{D}_{2} \mathrm{O}$ and the much shorter $\mathrm{S}_{3}$-state lifetimes at low $\mathrm{pH}$ (high proton concentration) are consistent with the need to take up a proton when returning to the $\mathrm{S}_{2}$ state. In line with this idea, no clear $\mathrm{H} / \mathrm{D}$ effect and a much weaker $\mathrm{pH}$ effect were observed on the rate of $S_{2}$ decay, which is not coupled to a proton uptake. This suggests that the $\mathrm{pH}$ has a strong effect on the redox potential of the $\mathrm{S}_{3}$ state, while the effect on $Q_{\mathrm{B}}{ }^{-}$is less important for the $\mathrm{S}_{i}$-state lifetimes. The sixfold acceleration of the $S_{0}$ oxidation to $S_{1}$ by $H / D$ exchange

Table 3 Fit parameters obtained during a global fit of a $2 \mathrm{~Hz}$ FIOP and $\mathrm{S}_{3}, \mathrm{~S}_{2}$, and $\mathrm{S}_{0}$ lifetime measurements of non-preflashed $C$. merolae thylakoids at $20^{\circ} \mathrm{C}$ and either at $\mathrm{pD} 6.1$ or at $\mathrm{pH} 6.1$

\begin{tabular}{lllll}
\hline $\mathrm{pL}$ & $\mathrm{pD} \mathrm{6.1}$ & $\mathrm{pD} \mathrm{6.1}$ & $\mathrm{pD} \mathrm{6.1}$ & $\mathrm{pH} \mathrm{6.1}$ \\
\hline$\alpha_{0}, \%$ & 12 & 0 & 0 & 0 \\
$\alpha_{1}, \%$ & 12 & 0 & 0 & 0 \\
$\alpha_{2}, \%$ & 12 & 37 & 0 & 35 \\
$\alpha_{3}, \%$ & 12 & 0 & 37 & 0 \\
$\beta, \%$ & 3.8 & 2.6 & 3.0 & 2.5 \\
$\mathrm{~d}, \%$ & 96 & 96 & 96 & 95 \\
$k_{32 \text { (fast) }}, \mathrm{s}^{-1}$ & $0.26^{\mathrm{a}}$ & 0.10 & 0.067 & 0.32 \\
$\mathrm{k}_{32 \text { (slow) }}, \mathrm{s}^{-1}$ & 0.0050 & 0.0050 & 0.0050 & 0.0029 \\
$k_{21 \text { (fast) }}, \mathrm{s}^{-1}$ & 2.9 & 2.8 & 2.6 & 1.4 \\
$\mathrm{k}_{21 \text { (slow) }}, \mathrm{s}^{-1}$ & 0.0010 & 0.0011 & 0.0011 & 0.0012 \\
$k_{01}, \mathrm{~s}^{-1}$ & 0.0014 & 0.0013 & 0.0012 & 0.0002 \\
Fit quality $\left(\times 10^{-8}\right)$ & 960 & 575 & 625 & 495 \\
\hline
\end{tabular}

${ }^{\text {a }}$ Rates for the fast $\mathrm{S}_{2}$ and $\mathrm{S}_{3}$ decay, as well as for $\mathrm{S}_{0}$ oxidation are less reliable due to the small $Y_{D}$ population giving insufficient constraints for fitting the fast $S_{2}$ and $S_{3}$ decays; they are displayed in italics 


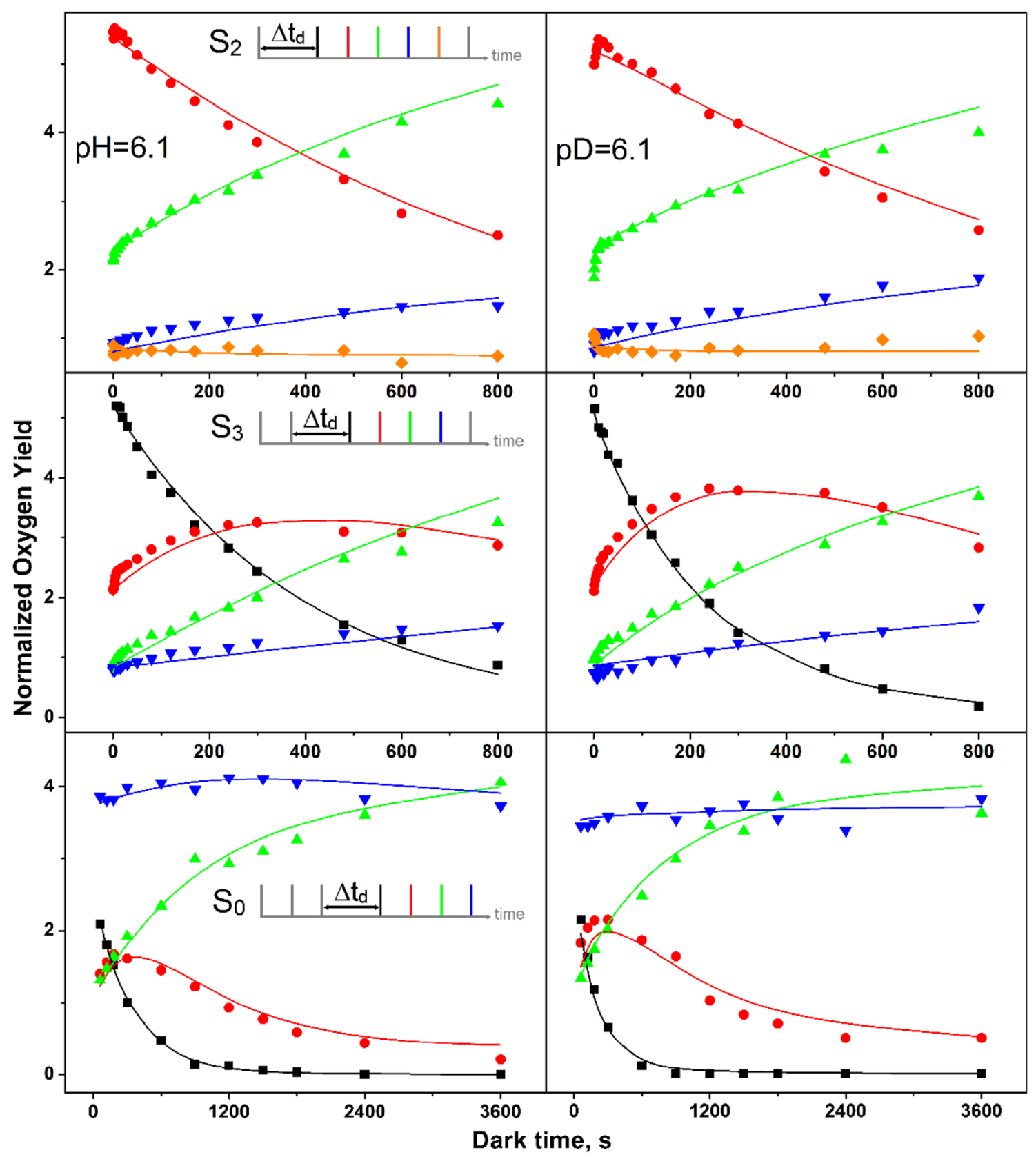

Fig. $5 \mathrm{~S}_{2^{-}}, \mathrm{S}_{3^{-}}$, and $\mathrm{S}_{0^{-}}$-state lifetime measurements at $\mathrm{pH} 6.1$ and $\mathrm{pD}$ 6.1. The normalized flash-induced oxygen yields of flashes 2-5 $\left(\mathrm{S}_{2}\right)$ or 1-4 $\left(\mathrm{S}_{3}, \mathrm{~S}_{0}\right)$ are plotted as a function of dark time between the preflash(es) and the flash train. The color code is given in the respec-

supports, indirectly, the surprising finding that low $\mathrm{pH}$ may induce the same effect (but even much stronger). The $\mathrm{S}_{0} Y_{\mathrm{D}}$ OX $\rightarrow \mathrm{S}_{1} \mathrm{Y}_{\mathrm{D}}$ reaction involves the following two half reactions:

$S_{0} \rightarrow S_{1}^{+}+e^{-} \rightarrow S_{1}+H^{+}+e^{-}$

$Y_{\mathrm{D}}^{o x}+H^{+}+e^{-} \rightarrow Y_{\mathrm{D}}$ tive inserts. Symbols are the experimental amplitudes, while the lines connect the amplitudes calculated by the global fitting program. Rate constants are given in Table 3, unequal miss fit

While the formation of the $S_{1}$ state should be faster at high $\mathrm{pH}$, the reduction of $Y_{\mathrm{D}}{ }^{\mathrm{OX}}$ may occur faster at low $\mathrm{pH}$. Indeed, a strong $\mathrm{H} / \mathrm{D}$ effect was observed for the reactions $\mathrm{S}_{2} Y_{\mathrm{D}} \rightarrow \mathrm{S}_{1} Y_{\mathrm{D}}{ }^{\text {OX }}$ and $\mathrm{S}_{3} Y_{\mathrm{D}} \rightarrow \mathrm{S}_{2} Y_{\mathrm{D}}$ OX and was linked to the position of a water molecule near $\mathrm{Y}_{\mathrm{D}}$ (Isgandarova 2004; Sjöholm et al. 2017). Zaharieva et al. (2011) observed a rapid inactivation of centers in the $\mathrm{S}_{0}$ state at low $\mathrm{pH}$ that occurs with a $\mathrm{pK}_{\mathrm{a}}$ of 4.6. We thus checked our data if a 
Table 4 Fit parameters obtained by using global or single fit of one $2 \mathrm{~Hz}$ FIOP and/or $\mathrm{S}_{3}, \mathrm{~S}_{2}$, and $\mathrm{S}_{0}$ lifetime measurements of (a) non-preflashed $C$. merolae thylakoids at $20^{\circ} \mathrm{C}$ and desired $\mathrm{pH}$ values, (b) spinach thylakoid at $10{ }^{\circ} \mathrm{C}$ and indicated $\mathrm{pH}$ values

\begin{tabular}{lllllll}
\hline & (a) C. merolae $20{ }^{\circ} \mathrm{C}$ & \multicolumn{5}{c}{ (b) Spinach $10{ }^{\circ} \mathrm{C}$} \\
\hline $\mathrm{pH}$ & 5.0 & 6.1 & 8.0 & 5.0 & 6.0 & 8.0 \\
$\alpha, \%$ & 18 & 11 & 22 & $\sim 12$ & $\sim 7.5$ & $\sim 9$ \\
$\beta, \%$ & 1.6 & 3.8 & 3.8 & $\sim 3.8$ & $\sim 2.5$ & $\sim 4$ \\
$k_{32 \text { (slow) }}, \mathrm{s}^{-1}$ & 0.0172 & 0.0030 & 0.0012 & 0.0173 & 0.0046 & 0.0013 \\
$k_{21 \text { (slow) }}, \mathrm{s}^{-1}$ & 0.0030 & 0.0015 & 0.0014 & 0.0026 & 0.0020 & 0.0021 \\
Reference & This study & & & Messinger and Renger (1994) &
\end{tabular}

\begin{tabular}{|c|c|c|c|c|c|c|}
\hline \multirow[b]{2}{*}{$\mathrm{pH}$} & \multicolumn{3}{|c|}{ C. merolae $20^{\circ} \mathrm{C}$} & \multicolumn{3}{|c|}{ Spinach $20{ }^{\circ} \mathrm{C}$} \\
\hline & 5.0 & 6.1 & 8.0 & 5.0 & 6.0 & 8.0 \\
\hline$\alpha, \%$ & 18 & 11 & 22 & 20 & 12 & 17 \\
\hline$\beta, \%$ & 1.6 & 3.8 & 3.8 & 2.9 & 2.1 & 2.0 \\
\hline Reference & \multicolumn{3}{|c|}{ This study } & \multicolumn{3}{|c|}{ Pham (2011) } \\
\hline
\end{tabular}

Table 5 Fit parameters obtained during fits of $2 \mathrm{~Hz}$ FIOPs of preflashed spinach thylakoids $\left(\mathrm{S}_{1} Y_{\mathrm{D}}^{\mathrm{OX}}\right)$ and $C$. merolae thylakoids at $20^{\circ} \mathrm{C}$ and indicated $\mathrm{pH}$ values specific slower phase of $S_{0}$ state inhibition could affect the $\mathrm{S}_{i}$ state quantitation; no indications for that was found (data not shown).

\section{Comparison to spinach}

Overall, the miss parameters and $\mathrm{S}_{i}$-state lifetimes found here for the PSII complex of the extremophilic red alga C. merolae were similar to those obtained earlier for spinach (Messinger and Renger 1994). This indicates that $C$. merolae PSII is not specifically adapted to acidic $\mathrm{pH}$ values, in agreement with earlier reports that the internal $\mathrm{pH}$ of $C$. merolae cells is regulated to values similar to those of higher plant chloroplasts. Consequently, the significantly different $Q_{\mathrm{A}}{ }^{-} / Q_{\mathrm{A}}$ midpoint potentials are not an adaptation to $\mathrm{pH}$, but more likely to growth temperature. This is supported by the nearly identical rates for the slow $\mathrm{S}_{2}$ and $\mathrm{S}_{3}$ state decays in C. merolae and spinach if measured at 20 and $10^{\circ} \mathrm{C}$, respectively (Table 4), which demonstrates the expected stabilization of the $\mathrm{S}$ states by the increased energy gap between $\mathrm{Pheo}^{-} / \mathrm{Pheo}$ and $Q_{\mathrm{A}}{ }^{-} / Q_{\mathrm{A}}$. In contrast, the average miss parameter is nearly identical between these two organisms at $\mathrm{pH} 5.0$ and 6.1 if measured at the same temperature $\left(20^{\circ} \mathrm{C}\right.$; Table 5), supporting the idea that it is determined by the unaltered donor side reactions.

\section{Conclusions}

Global fits of the $\mathrm{S}_{3^{-}}, \mathrm{S}_{2^{-}}$, and $\mathrm{S}_{1^{-}}$-state lifetime measurements provide a powerful tool for studying the efficiency of PSII complexes under various conditions, in different species or mutants. By comparing the data obtained here with $C$. merolae thylakoids to our previous spinach data, we have demonstrated that the redox potential of $Q_{\mathrm{A}}{ }^{-} / Q_{\mathrm{A}}$ plays only a minor role for the miss parameter, but instead mostly affects the $\mathrm{S}_{i}$-state lifetimes. This is likely due to the increased energy gap between the $Q_{\mathrm{A}}{ }^{-} / Q_{\mathrm{A}}$ and $\mathrm{Pheo}^{-} / \mathrm{Pheo}$ redox pairs, which increases the barrier for the acceptor side electrons for recombination with the holes on the donor side, which occurs via the pheophytin cofactor (see Fig. 2). In addition, our data support the notion that the $S_{2} \rightarrow S_{3}$ transition is, at neutral $\mathrm{pH}$, the least efficient step during the oxidation of water to molecular oxygen in the watersplitting enzyme, possibly due to the significant conformational changes occurring during the $\mathrm{S}_{2} \rightarrow \mathrm{S}_{3}$ transition, which include the binding of one water molecule (Suzuki et al. 2008; Siegbahn 2009; Capone et al. 2016; Retegan et al. 2016; Ugur et al. 2016; Kim and Debus 2017; Suga et al. 2017).

Acknowledgements LVP and JM were supported by the Swedish Research Council (VR, 2016-05183_3), the Swedish Energy Agency (2013-006259, project 38239-1), the Swedish Research Council FORMAS (213-2014-1504), and NordForsk (NordAqua NCoE, 82845). JK and JDJO gratefully acknowledge the financial support from the Polish National Science Centre (Grant No. UMO-2014/15/B/NZ1/00975 to $\mathrm{JK})$.

Open Access This article is distributed under the terms of the Creative Commons Attribution 4.0 International License (http://creativeco mmons.org/licenses/by/4.0/), which permits unrestricted use, distribution, and reproduction in any medium, provided you give appropriate credit to the original author(s) and the source, provide a link to the Creative Commons license, and indicate if changes were made.

\section{References}

Aebi H (1984) Catalase in vitro. Meth Enzymol 105:121-126 
Ago H, Adachi H, Umena Y, Tashiro T, Kawakami K, Kamiya N, Tian LR, Han GY, Kuang TY, Liu ZY, Wang FJ, Zou HF, Enami I, Miyano M, Shen JR (2016) Novel features of eukaryotic photosystem ii revealed by its crystal structure analysis from a red alga. J Biol Chem 291:5676-5687

Allakhverdiev SI, Tomo T, Shimada Y, Kindo H, Nagao R, Klimov VV, Mimuro M (2010) Redox potential of pheophytin a in photosystem II of two cyanobacteria having the different special pair chlorophylls. Proc Acad Natl Sci USA 107:3924-3929

Allakhverdiev SI, Tsuchiya T, Watabe K, Kojima A, Los DA, Tomo T, Klimov VV, Mimuro M (2011) Redox potentials of primary electron acceptor quinone molecule $\left(\mathrm{Q}_{\mathrm{A}}\right)^{-}$and conserved energetics of photosystem II in cyanobacteria with chlorophyll a and chlorophyll d. Proc Acad Natl Sci USA 108:8054-8058

Barber J (2009) Photosynthetic energy conversion: natural and artificial. Chem Soc Rev 38:185-196

Beers RF, Sizer IW (1952) A spectrophotometric method for measuring the breakdown of hydrogen peroxide by catalase. J Biol Chem 195:133-140

Blankenship RE (2014) Molecular mechanism of photosynthesis, 2nd edn. Wiley Blackwell, Hoboken

Bradford MM (1976) Rapid and sensitive method for quantitation of microgram quantities of protein utilizing principle of protein-dye binding. Anal Biochem 72:248-254

Capone M, Narzi D, Bovi D, Guidoni L (2016) Mechanism of water delivery to the active site of photosystem II along the $S_{2}$ to $S_{3}$ transition. J Phys Chem Lett 7:592-596

Cardona T, Murray JW, Rutherford AW (2015) Origin and evolution of water oxidation before the last common ancestor of the cyanobacteria. Mol Biol Evol 32:1310-1328

Christen G, Seeliger A, Renger G (1999) P680 reduction kinetics and redox transition probability of the water oxidizing complex as a function of $\mathrm{pH}$ and $\mathrm{H} / \mathrm{D}$ isotope exchange in spinach thylakoids. Biochemistry 38:6082-6092

Cinco RM, Holman KLM, Robblee JH, Yano J, Pizarro SA, Bellacchio E, Sauer K, Yachandra VK (2002) Calcium EXAFS establishes the Mn-Ca cluster in the oxygen-evolving complex of photosystem II. Biochemistry 41:12928-12933

Ciniglia C, Yoon HS, Pollio A, Pinto G, Bhattacharya D (2004) Hidden biodiversity of the extremophilic Cyanidiales red algae. Mol Ecol 13:1827-1838

Cox N, Retegan M, Neese F, Pantazis DA, Boussac A, Lubitz W (2014) Electronic structure of the oxygen evolving complex in photosystem II prior to O-O bond formation. Science 345:804-808

Dau H, Haumann M (2007) Eight steps preceding O-O bond formation in oxygenic photosynthesis-a basic reaction cycle of the photosystem II manganese complex. Biochim Biophys Acta 1767:472-483

Dau H, Haumann M (2008) The manganese complex of photosystem II in its reaction cycle-basic framework and possible realization at the atomic level. Coordin Chem Rev 252:273-295

de Wijn R, van Gorkom HJ (2002) S-state dependence of the miss probability in photosystem II. Photosynth Res 72:217-222

Delrieu MJ (1974) Simple explanation of misses in cooperation of charges in photosynthetic $\mathrm{O}_{2}$ evolution. Photochem Photobiol 20:441-454

Diner BA (1977) Dependence of deactivation reactions of pohotosystem II on redox state of plastoquinone pool A varied under anaerobic conditions. Equilibria on acceptor side of photosystem II. Biochim Biophys Acta 460:247-258

Enami I, Adachi H, Shen JR (2010) Mechanisms of acido-tolerance and characteristics of photosystems in an acidophilic and thermophilic red alga, Cyanidium caldarium. In: Seckbach J, Chapman DJ (eds) Red algae in the genomic age. Springer, Dordrecht, pp 375-389
Ferreira KN, Iverson TM, Maghlaoui K, Barber J, Iwata S (2004) Architecture of the photosynthetic oxygen-evolving center. Science 303:1831-1838

Ferris MJ, Sheehan KB, Kuhl M, Cooksey K, Wigglesworth-Cooksey B, Harvey R, Henson JM (2005) Algal species and light microenvironment in a low-pH, geothermal microbial mat community. Appl Environ Microbiol 71:7164-7171

Forbush B, Kok B, McGloin MP (1971) Cooperation of charges in photosynthetic $\mathrm{O}_{2}$ evolution-II. Damping of flash yield oscillation, deactivation. Photochem Photobiol 14:307-321

Glöckner C, Kern J, Broser M, Zouni A, Yachandra V, Yano J (2013) Structural changes of the oxygen-evolving complex in photosystem II during the catalytic cycle. J Biol Chem 288:22607-22620

Govindjee, Beatty J, Gest H, Allen J (2005) Discoveries in photosynthesis. Advances in photosynthesis and respiration. Springer, Dordrecht

Han GY, Mamedov F, Styring S (2012) Misses during water oxidation in photosystem II are S-state dependent. J Biol Chem 287:13422-13429

Haniewicz P, Abram M, Nosek L, Kirkpatrick J, El-Mohsnawy E, Janna Olmos J, Kouril R, Kargul J (2018) Molecular mechanisms of photoadaptation of photosystem I supercomplex from an evolutionary cyanobacterial/algal intermediate. Plant Physiol 176:1433-1451

Haumann M, Müller C, Liebisch P, Iuzzolino L, Dittmer J, Grabolle M, Neisius T, Meyer-Klaucke W, Dau H (2005) Structural and oxidation state changes of the photosystem II manganese complex in four transitions of the water oxidation cycle $\left(\mathrm{S}_{0} \rightarrow\right.$ $\mathrm{S}_{1}, \mathrm{~S}_{1} \rightarrow \mathrm{S}_{2}, \mathrm{~S}_{2} \rightarrow \mathrm{S}_{3}$, and $\mathrm{S}_{3,4} \rightarrow \mathrm{S}_{0}$ ) characterized by X-ray absorption spectroscopy at $20 \mathrm{~K}$ and room temperature. Biochemistry 44:1894-1908

Isgandarova S (2004) Studies on mechanism of the photosynthetic water oxidation in thermophilic cyanobacterium Thermosynechococcus elongatus and spinach $\mathrm{PhD}$ thesis, Technical University of Berlin (TU Berlin)

Isgandarova S, Renger G, Messinger J (2003) Functional differences of photosystem II from Synechococcus elongatus and spinach characterized by flash induced oxygen evolution patterns. Biochemistry 42:8929-8938

Joliot P (1972) Modulated light source use with the oxygen electrode. Meth Enzymol 24:123-134

Joliot P, Kok B (1975) Oxygen evolution in photosynthesis. In: Govindjee (ed) Bioenergetics of photosynthesis. Academic Press, New York, pp 387-412

Joliot P, Barbieri G, Chabaud R (1969) Un nouveau modele des centres photochimiques du systeme II. Photochem Photobiol 10:309-329

Kim CJ, Debus RJ (2017) Evidence from FTIR difference spectroscopy that a substrate $\mathrm{H}_{2} \mathrm{O}$ molecule for $\mathrm{O}_{2}$ formation in photosystem II is provided by the $\mathrm{Ca}$ ion of the catalytic $\mathrm{Mn}_{4} \mathrm{CaO}_{5}$ cluster. Biochemistry 56:2558-2570

Klauss A, Haumann M, Dau H (2012) Alternating electron and proton transfer steps in photosynthetic water oxidation. Proc Natl Acad Sci USA 109:16035-16040

Klauss A, Haumann M, Dau H (2015) Seven steps of alternating electron and proton transfer in photosystem II water oxidation traced by time-resolved photothermal beam deflection at improved sensitivity. J Phys Chem B 119:2677-2689

Kok B, Forbush B, McGloin M (1970) Cooperation of charges in photosynthetic $\mathrm{O}_{2}$ evolution-I. A linear four step mechanism. Photochem Photobiol 11:457-475

Krewald V, Retegan M, Cox N, Messinger J, Lubitz W, DeBeer S, Neese F, Pantazis DA (2015) Metal oxidation states in biological water splitting. Chem Sci 6:1676-1695 
Krupnik T, Kotabova E, van Bezouwen LS, Mazur R, Garstka M, Nixon PJ, Barber J, Kana R, Boekema EJ, Kargul J (2013) A reaction center-dependent photoprotection mechanism in a highly robust photosystem ii from an extremophilic red alga, Cyanidioschyzon merolae. J Biol Chem 288:23529-23542

Kulik LV, Epel B, Lubitz W, Messinger J (2007) Electronic structure of the $\mathrm{Mn}_{4} \mathrm{O}_{\mathrm{x}}$ Ca cluster in the $\mathrm{S}_{0}$ and $\mathrm{S}_{2}$ states of the oxygen-evolving complex of photosystem II based on pulse ${ }^{55} \mathrm{Mn}$-ENDOR and EPR Spectroscopy. J Am Chem Soc 129:13421-13435

Lavergne J, Junge W (1993) Proton release during the redox cycle of the water oxidase. Photosynth Res 38:279-296

Mamedov M, Govindjee, Nadtochenko V, Semenov A (2015) Primary electron transfer processes in photosynthetic reaction centers from oxygenic organisms. Photosynth Res 125:51-63

Mar T, Govindjee (1972) Kinetic models of oxygen evolution in photosynthesis. J Theor Biol 36:427-446

Messinger J, Renger G (1993) Generation, oxidation by the oxidized form of the tyrosine of polypeptide $\mathrm{D} 2$, and possible electronic configuration of the redox states $\mathrm{S}_{0}, \mathrm{~S}_{-1}$, and $\mathrm{S}_{-2}$ of the water oxidase in isolated spinach thylakoids. Biochemistry 32:9379-9386

Messinger J, Renger G (1994) Analyses of pH-Induced modifications of the period four oscillation of flash-induced oxygen evolution reveal distinct structural changes of the photosystem II donor side at characteristic pH values. Biochemistry 33:10896-10905

Messinger J, Renger G (2008) Photosynthetic water splitting. G. Renger. In: Primary processes of photosynthesis - Part 2: basic principles and apparatus. The Royal Society of Chemistry, Cambridge, pp 291-349

Messinger J, Robblee JH, Yu WO, Sauer K, Yachandra VK, Klein MP (1997) The $S_{0}$ state of the oxygen-evolving complex in photosystem II is paramagnetic: detection of EPR multiline signal. J Am Chem Soc 119:11349-11350

Meunier PC, Popovic R (1990) Control of misses in oxygen evolution by the oxidoreduction state of plastoquinone in dunaliellatertiolecta. Photosynth Res 23:213-221

Mirkovic T, Ostroumov EE, Anna JM, van Grondelle R, Govindjee, Scholes GD (2017) Light absorption and energy transfer in the antenna complexes of photosynthetic organisms. Chem Rev 117:249-293

Naber JD, Vanrensen JJS, Govindjee (1993) High misses after odd flashes in oxygen evolution in thoroughly dark-adapted thylakoids from pea and chenopodium-album. Photosynth Res 38:309-314

Nakamura S, Ota K, Shibuya Y, Noguchi T (2016) Role of a water network around the $\mathrm{Mn}_{4} \mathrm{CaO}_{5}$ cluster in photosynthetic water oxidation: a fourier transform infrared spectroscopy and quantum mechanics/molecular mechanics calculation study. Biochemistry 55:597-607

Nilsson H, Cournac L, Rappaport F, Messinger J, Lavergne J (2016) Estimation of the driving force for dioxygen formation in photosynthesis. Biochim Biophys Acta 1857:23-33

Nugent JHA, Demetriou C, Lockett CJ (1987) Electron donation in photosystem II. Biochim Biophys Acta 894:534-542

Ohta H, Suzuki T, Ueno M, Okumura A, Yoshihara S, Shen JR, Enami I (2003) Extrinsic proteins of photosystem II. An intermediate member of the PsbQ protein family in red algal PSII. Eur J Biochem 270:4156-4163

Peloquin JM, Campbell KA, Randall DW, Evanchik MA, Pecoraro VL, Armstrong WH, Britt RD (2000) ${ }^{55} \mathrm{Mn}$ ENDOR of the $\mathrm{S}_{2}$-state multiline EPR signal of photosystem II: implications on the structure of the tetranuclear Mn cluster. J Am Chem Soc 122:10926-10942

Pham LV (2011) Flash-induced oxygen evolution measurements in photosystem II samples. Master thesis, Umeå University
Pham LV, Messinger J (2014) Electrochemically produced hydrogen peroxide affects Joliot-type oxygen-evolution measurements of photosystem II. Biochim Biophys Acta 1837:1411-1416

Pham LV, Messinger J (2016) Probing S-state advancements and recombination pathways in photosystem II with a global fit program for flash-induced oxygen evolution pattern. Biochim Biophys Acta 1857:848-859

Rappaport F, Lavergne J (1991) Proton release during successive oxidation steps of the photosynthetic water oxidation process-stoichiometries and pH-dependence. Biochemistry 30:10004-10012

Rappaport F, Lavergne J (1997) Charge recombination and proton transfer in manganese-depleted photosystem II. Biochemistry 36:15294-15302

Rappaport F, Lavergne J (2001) Coupling of electron and proton transfer in the photosynthetic water oxidase. Biochim Biophys Acta 1503:246-259

Rappaport F, Blancharddesce M, Lavergne J (1994) Kinetics of electron-transfer and electrochromic change during the redox transitions of the photosynthetic oxygen-evolving complex. Biochim Biophys Acta 1184:178-192

Rappaport F, Ishida N, Sugiura M, Boussac A (2011) $\mathrm{Ca}^{2+}$ determines the entropy changes associated with the formation of transition states during water oxidation by Photosystem II. Energ Environ Sci 4:2520-2524

Renger G (2008) Primary processes in photosynthesis. RSC Publishing, Cambridge

Renger G, Hanssum B (1988) Studies on the deconvolution of flashinduced absorption changes into the difference spectra of individual redox steps within the water-oxidizing enzyme system. Photosynth Res 16:243-259

Renger G, Renger T (2008) Photosystem II: the machinery of photosynthetic water splitting. Photosynth Res 98:53-80

Retegan M, Krewald V, Mamedov F, Neese F, Lubitz W, Cox N, Pantazis DA (2016) A five-coordinate Mn(IV) intermediate in biological water oxidation: spectroscopic signature and a pivot mechanism for water binding. Chem Sci 7:72-84

Robblee JH, Messinger J, Cinco RM, McFarlane KL, Fernandez C, Pizarro SA, Sauer K, Yachandra VK (2002) The Mn cluster in the $\mathrm{S}_{0}$ state of the oxygen-evolving complex of photosystem II studied by EXAFS spectroscopy: are there three di-mu-oxobridged $\mathrm{Mn}_{2}$ moieties in the tetranuclear Mn complex? J Am Chem Soc 124:7459-7471

Robinson HH, Crofts AR (1983) Kinetics of the oxidation reduction reactions of the photosystem II quinone acceptor complex, and the pathway for deactivation. FEBS Lett 153:221-226

Romero E, Novoderezhkin VI, van Grondelle R (2017) Quantum design of photosynthesis for bio-inspired solar-energy conversion. Nature 543:355-365

Rutherford AW, Inoue Y (1984) Oscillation of delayed luminescence from PS II: recombination of $\mathrm{S}_{2} \mathrm{Q}_{\mathrm{B}}{ }^{-}$and $\mathrm{S}_{3} \mathrm{Q}_{\mathrm{B}}{ }^{-}$. FEBS Lett 165:163-170

Rutherford AW, Crofts AR, Inoue Y (1982) Thermoluminescence as a probe of photosystem II photochemistry. The origin of the flashinduced glow peaks. Biochim Biophys Acta 682:457-465

Saito K, Rutherford AW, Ishikita H (2013) Mechanism of tyrosine D oxidation in Photosystem II. Proc Natl Acad Sci USA 110:7690-7695

Schlodder E, Witt HT (1999) Stoichiometry of proton release from the catalytic center in photosynthetic water oxidation-reexamination by a glass electrode study at $\mathrm{pH} 5.5-7.2$. J Biol Chem 274:30387-30392

Sedmak JJ, Grossberg SE (1977) Rapid, sensitive, and versatile assay for protein using Coomassie Brilliant Blue G250. Anal Biochem 79:544-552

Service RJ, Hillier W, Debus RJ (2010) Evidence from FTIR difference spectroscopy of an extensive network of hydrogen bonds 
near the oxygen-evolving Mn4Ca cluster of photosystem II involving D1-Glu65, D2-Glu312, and D1-Glu329. Biochemistry 49:6655-6669

Shevela D, Eaton-Rye JJ, Shen JR, Govindjee (2012) Photosystem II and the unique role of bicarbonate: a historical perspective. Biochim Biophys Acta 1817:1134-1151

Shibamoto T, Kato Y, Nagao R, Yamazaki T, Tomo T, Watanabe T (2010) Species-dependence of the redox potential of the primary quinone electron acceptor $\mathrm{Q}_{\mathrm{A}}$ in photosystem II verified by spectroelectrochemistry. FEBS Lett 584:1526-1530

Shinkarev VP, Wraight CA (1993) Oxygen evolution in photosynthesis-from unicycle to bicycle. Proc Natl Acad Sci USA 90:1834-1838

Shoji M, Isobe H, Yamanaka S, Umena Y, Kawakami K, Kamiya N, Shen JR, Yamaguchi K (2013) Theoretical insight in to hydrogen-bonding networks and proton wire for the $\mathrm{CaMn}_{4} \mathrm{O}_{5}$ cluster of photosystem II. Elongation of $\mathrm{Mn}-\mathrm{Mn}$ distances with hydrogen bonds. Catal Sci Tech 3:1831-1848

Siegbahn PEM (2009) Structures and energetics for $\mathrm{O}_{2}$ formation in photosystem II. Acc Chem Res 42:1871-1880

Siegbahn PEM (2013) Water oxidation mechanism in photosystem II, including oxidations, proton release pathways, $\mathrm{O}-\mathrm{O}$ bond formation and $\mathrm{O}_{2}$ release. Biochim Biophys Acta 1827:1003-1019

Sjöholm J, Ho F, Ahmadova N, Brinkert K, Hammarstrom L, Mamedov F, Styring S (2017) The protonation state around $\operatorname{Tyr}_{\mathrm{D}} / \operatorname{Tyr}_{\mathrm{D}}{ }^{\bullet}$ in photosystem II is reflected in its biphasic oxidation kinetics. Biochim Biophys Acta 1858:147-155

Styring S, Rutherford AW (1987) In the oxygen evolving complex of photosystem II the $\mathrm{S}_{0}$ state is oxidized to the $\mathrm{S}_{1}$ state by $\mathrm{D}^{+}$(signal $\mathrm{II}_{\text {slow }}$ ). Biochemistry 26:2401-2405

Styring S, Rutherford AW (1988) Deactivation kinetics and temperature dependence of the S-state transitions in the oxygen-evolving system of photosystem II measured by EPR spectroscopy. Biochim Biophys Acta 933:378-387

Suga M, Akita F, Hirata K, Ueno G, Murakami H, Nakajima Y, Shimizu T, Yamashita K, Yamamoto M, Ago H, Shen JR (2015) Native structure of photosystem II at $1.95 \AA$ resolution viewed by femtosecond X-ray pulses. Nature 517:99-103

Suga M, Akita F, Sugahara M, Kubo M, Nakajima Y, Nakane T, Yamashita K, Umena Y, Nakabayashi M, Yamane T, Nakano T, Suzuki M, Masuda T, Inoue S, Kimura T, Nomura T, Yonekura S, Yu LJ, Sakamoto T, Motomura T, Chen JH, Kato Y, Noguchi T, Tono K, Joti Y, Kameshima T, Hatsui T, Nango E, Tanaka R, Naitow H, Matsuura Y, Yamashita A, Yamamoto M, Nureki O, Yabashi M, Ishikawa T, Iwata S, Shen JR (2017) Light-induced structural changes and the site of $\mathrm{O}=\mathrm{O}$ bond formation in PSII caught by XFEL. Nature 543:131-135

Suzuki H, Sugiura M, Noguchi T (2008) Monitoring water reactions during the S-state cycle of the photosynthetic water-oxidizing center: detection of the DOD bending vibrations by means of Fourier transform infrared spectroscopy. Biochemistry 47:11024-11030

Suzuki H, Sugiura M, Noguchi T (2012) Determination of the miss probabilities of individual S-state transitions during photosynthetic water oxidation by monitoring electron flow in photosystem II using FTIR spectroscopy. Biochemistry 51:6776-6785
Ugur I, Rutherford AW, Kaila VRI (2016) Redox-coupled substrate water reorganization in the active site of photosystem II: the role of calcium in substrate water delivery. Biochim Biophys Acta 1857:740-748

Umena Y, Kawakami K, Shen JR, Kamiya N (2011) Crystal structure of oxygen-evolving photosystem II at a resolution of $1.9 \AA$. Nature 473:55-60

Vass I, Styring S (1991) pH-dependent charge equilibria between tyrosine $\mathrm{D}$ and the $\mathrm{S}$-states in photosystem II. Estimation of relative midpoint redox potentials. Biochemistry 30:830-839

Vass I, Deak Z, Hideg E (1990) Charge equilibrium between the wateroxidizing complex and the electron donor tyrosine-D in photosystem II. Biochim Biophys Acta 1017:63-69

Vermaas WFJ, Renger G, Dohnt G (1984) The reduction of the oxygenevolving system in chloroplasts by thylakoid components. Biochim Biophys Acta 764:194-202

Vermaas WFJ, Rutherford AW, Hansson Ö (1988) Site-directed mutagenesis in photosystem II of the cyanobacterium Synechocystis sp. PCC 6803: donor D is a tyrosine residue in the D2 protein. Proc Natl Acad Sci USA 85:8477-8481

Yamada M, Nagao R, Iwai M, Arai Y, Makita A, Ohta H, Tomo T (2018) The PsbQ' protein affects the redox potential of the $Q_{A}$ in photosystem II. Photosynthetica 56:185-191

Yano J, Yachandra V (2014) Mn4Ca Cluster in photosynthesis: where and how water is oxidized to dioxygen. Chem Rev 114:4175-4205

Yano J, Kern J, Sauer K, Latimer MJ, Pushkar Y, Biesiadka J, Loll B, Saenger W, Messinger J, Zouni A, Yachandra VK (2006) Where water is oxidized to dioxygen: structure of the photosynthetic $\mathrm{Mn}_{4} \mathrm{Ca}$ cluster. Science 314:821-825

Young ID, Ibrahim M, Chatterjee R, Gul S, Fuller FD, Koroidov S, Brewster AS, Tran R, Alonso-Mori R, Kroll T, Michels-Clark T, Laksmono H, Sierra RG, Stan CA, Hussein R, Zhang M, Douthit L, Kubin M, de Lichtenberg C, Vo Pham L, Nilsson H, Cheah MH, Shevela D, Saracini C, Bean MA, Seuffert I, Sokaras D, Weng TC, Pastor E, Weninger C, Fransson T, Lassalle L, Brauer P, Aller P, Docker PT, Andi B, Orville AM, Glownia JM, Nelson S, Sikorski M, Zhu D, Hunter MS, Lane TJ, Aquila A, Koglin JE, Robinson J, Liang M, Boutet S, Lyubimov AY, Uervirojnangkoorn M, Moriarty NW, Liebschner D, Afonine PV, Waterman DG, Evans G, Wernet P, Dobbek H, Weis WI, Brunger AT, Zwart PH, Adams PD, Zouni A, Messinger J, Bergmann U, Sauter NK, Kern J, Yachandra VK, Yano J (2016) Structure of photosystem II and substrate binding at room temperature. Nature 540:453-457

Zaharieva I, Wichmann JM, Dau H (2011) Thermodynamic limitations of photosynthetic water oxidation at high proton concentrations. J Biol Chem 286:18222-18228

Zenvirth D, Volokita M, Kaplan A (1985) Photosynthesis and inorganic carbon accumulation in the acidophilic alga Cyanidioschyzon merolae. Plant Physiol 77:237-239

Zouni A, Witt HT, Kern J, Fromme P, Krauss N, Saenger W, Orth P (2001) Crystal structure of photosystem II from Synechococcus elongatus at 3.8 A resolution. Nature 409:739-743 